\title{
Synthesis of Bi- and Trifunctional Cyclic Carbonates Based on Trimethylolpropane and Their Application to Networked Polyhydroxyurethanes
}

\author{
Hiroyuki Matsukizono ${ }^{1} \&$ Takeshi Endo ${ }^{1}$ \\ ${ }^{1}$ Molecular Engineering Institute, Kinki University, Japan \\ Correspondence: Takeshi Endo, Professor of Molecular Engineering Institute, Kinki University, 11-6 Kayanomori, \\ Iizuka, Fukuoka, 820-8555, Japan. Tel: 81-948-228-042. E-mail: tendo@moleng.fuk.kindai.ac.jp
}

Received: January 22, 2016

doi:10.5539/jmsr.v5n3p11
Accepted: March 3, 2016 Online Published: April 7, 2016

URL: http://dx.doi.org/10.5539/jmsr.v5n3p11

\begin{abstract}
The reaction of trimethylolpropane (TMP) and diphenyl carbonate gives three types of TMP-based six-membered cyclic carbonates (TMPCs) via phosgene-free route. TMPC having one hydroxyl group (TMPC-OH) reacted with terephthaloyl chloride or trimesoyl chloride to give bifunctional $\left(\mathrm{Ph}-\mathrm{TMPC}_{2}\right)$ or trifunctional cyclic carbonate monomers $\left(\mathrm{Ph}-\mathrm{TMPC}_{3}\right)$, respectively. The ring-opening polyaddition of $\mathrm{Ph}-\mathrm{TMPC}_{2}$ and conventional diamines efficiently proceeded without the cleavage of ester bonds to afford linear polyhydroxyurethanes (PHUs) with well-controlled molecular weights and polydispersities via isocyanate-free route. Moreover, the polyaddition of $\mathrm{Ph}-\mathrm{TMPC}_{2}$ and diamine at $\mathrm{TMPC}_{2} /$ diamine feed ratio of 1.1 afforded PHUs having cyclic carbonate terminals, the hydroxyl side chains of which were easily reacted with acetic anhydride to give acetylated PHUs with cyclic carbonate terminals. On the other hand, the polyaddition at $\mathrm{Ph}-\mathrm{TMPC}_{2} /$ diamine feed ratio of 0.91 gave PHUs with amine terminals. The copolymerization of $\mathrm{Ph}-\mathrm{TMPC}_{2}, \mathrm{Ph}-\mathrm{TMPC}_{3}$ and diamine gives $\mathrm{PHUs}$ comprising covalently-bridged networked structures. After DMF solutions of $\mathrm{Ph}-\mathrm{TMPC}_{2}, \mathrm{Ph}-\mathrm{TMPC}_{3}$ and diamines were simply kept at $60{ }^{\circ} \mathrm{C}$ overnight, networked PHU films with well transparency were successfully fabricated. The PHU films prepared at different diamines showed similar transparency and thermal stability, while the mechanical properties were significantly affected by the methylene spacers of diamines.
\end{abstract}

Keywords: trimethylolpropane, diphenyl carbonate, networked polyhydroxyurethane, polyhydroxyurethane film

\section{Introduction}

Poly(hydroxyurethane)s (PHUs) have been attracting great interest as the promising alternatives of widely-used polyurethanes because PHUs can be synthesized by ring-opening polyaddition of bifunctional cyclic carbonates and diamines without using toxic isocyanates (Nohra, 2013; Kathalewar, 2013). In particular, five-membered cyclic carbonates (5-CCs) can be derived from epoxides and $\mathrm{CO}_{2}$ under mild conditions (Fleischer, 2013; Sheng, 2015) and therefore, numerous 5-CCs-derived PHUs have been synthesized using bisphenol A (Ochiai, 2014; Lambeth, 2013; Ochiai, 2007; Ochiai, 2005; Kihara, 1996) and bio-based polyols (Kathalewar, 2015; Maisonneuve, 2014; Annunziata, 2014; Guillaume, 2013; Guillaume, 2011) as starting materials. PHUs can be functionalized by the use of functional diamines or by chemical modifications via their hydroxyl side chains. Nowadays it has been reported that silicone-conjugated PHUs show lower glass transition temperatures and well water repelling properties (Ochiai, 2014) and networked PHU gels are obtainable by the reaction with metal alkoxides (Kihara, 1996) or by the free-radical polymerization of methacryl groups modified in their side chains (Ochiai, 2007). In addition, urethane linkages of PHUs can be degraded at alkaline conditions and further shows biodegradability, thus, PHUs are one of promising candidates for versatile materials based on biocompatibility and biodegradability. Meanwhile, PHUs from six-membered cyclic carbonates (6-CCs) are hardly reported except for a few case (He, 2011; Maisonneuve, 2014; Tomita, 2001). The ring-opening reaction of 6-CCs with amines requires the lower energy compared to 5-CCs because of the larger ring strain energy of 6-CCs (Tomita, 2001). This implies that PHUs can be synthesized at milder conditions. Besides, $\beta$-substituted 6-CCs generate only primary alcohols (hydroxymethyl groups) after the ring-opening reaction with amines, therefore, simple structured PHUs are obtainable. However, 6-CCs are generally synthesized using toxic phosgene or its derivatives (He, 2011; Maisonneuve, 2014; Tomita, 2001), which hinders the practical usage of 6-CCs and their application to PHU materials. 
The development of synthetic route to 6-CCs without toxic phosgene and its derivatives is one of important issues in polycarbonate and polyurethane chemistry. It has been reported that the synthesis of mono- and bifunctional 6-CCs using diphenyl carbonate (DPC) and their application to networked polycarbonate and PHU films via their copolymerization (Matsukizono, 2015, 2016). Without phosgene and its derivatives, DPC can be synthesized from ethylene carbonates through the reaction with methanol and phenol (Nishihara, 2010; Okuyama, 2003) or from CO and phenol (Kanega, 2013; Murayama, 2012). Furthermore, Matsukizono and Endo (2016) have recently reported that the reaction of trimethylolpropane (TMP) with an excess amount of DPC gives three types of different structured TMP-based cyclic carbonates (TMPCs) shown in Scheme 1: TMPC bearing a hydroxyl group (TMPC-OH), TMPC bearing a phenoxycarbonylated hydroxyl group (TMPC-OCOPh) and TMPC dimers bridged by an acyclic carbonate bond (TMPC-dimer). In addition, they have reacted TMPC-dimer with conventional diamine to form poly(carbonate-hydroxyurethane)s and characterized their hydrolytic properties in basic aqueous media. Meanwhile, TMPC-OH contains one hydroxyl group, which can be reacted with multifunctional acyl chloride to synthesize multifunctional 6-CCs bridged by ester linkages. This approach lets us expect that networked PHU materials such as gels and films can be easily fabricated by the simple reaction of multifunctional 6-CCs with diamines.

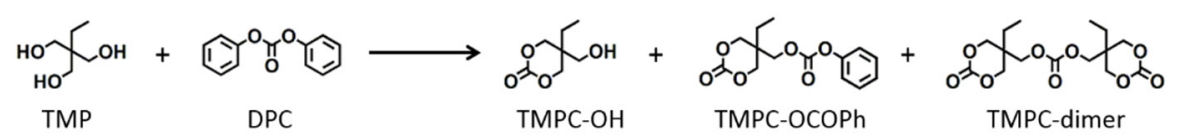

Scheme 1. Three types of different structured cyclic carbonates synthesized by the reaction of TMP and DPC

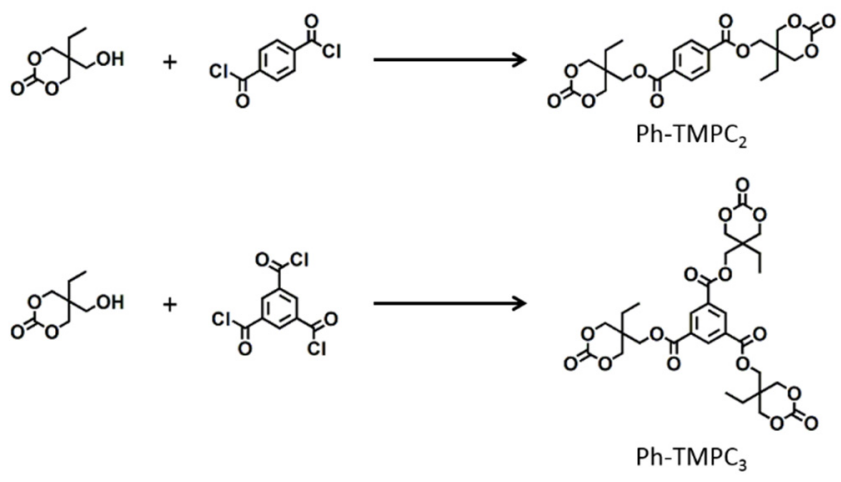

Scheme 2. Synthesis of bifunctional 6-CCs $\left(\mathrm{Ph}-\mathrm{TMPC}_{2}\right)$ or trifunctional 6-CCs $\left(\mathrm{Ph}-\mathrm{TMPC}_{3}\right)$ from TMPC-OH.

Here in, we describe the facile fabrication route to networked PHU material. At first, we synthesized bi- and trifunctional 6-CCs from TMPC-OH ( $\mathrm{Ph}-\mathrm{TMPC}_{2}$ and $\mathrm{Ph}_{-} \mathrm{TMPC}_{3}$ ) (See Scheme 2). Next, we performed the ring-opening polyaddition of $\mathrm{Ph}-\mathrm{TMPC}_{2}$ and conventional diamines to yield linear PHUs (Scheme 3a). Finally, we reacted $\mathrm{Ph}-\mathrm{TMPC}_{2}, \mathrm{Ph}-\mathrm{TMPC}_{3}$ and diamines at different feed ratios to build networked PHU films and characterized their transparency, thermal stability and mechanical properties (Scheme $3 \mathrm{~b}$ ). Monomers and polymers were analyzed by ${ }^{1} \mathrm{H}$ and ${ }^{13} \mathrm{C}$ nuclear magnetic resonance (NMR), Fourier translation infra-red (FT-IR) spectroscopy, size exclusion chromatography (SEC), thermogravimetric analysis (TGA), UV/Vis.-near infra-red (NIR) absorption spectroscopy and tensile tests. 
a)

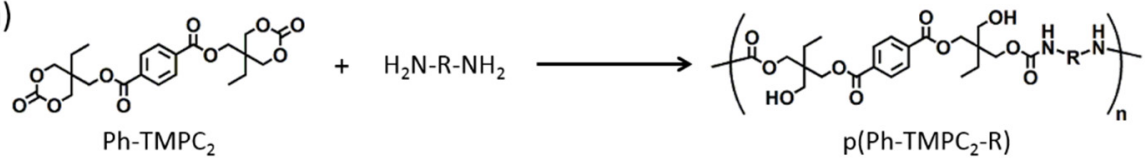

b)

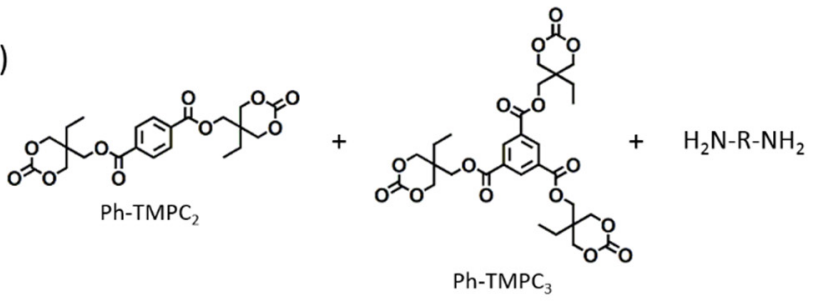

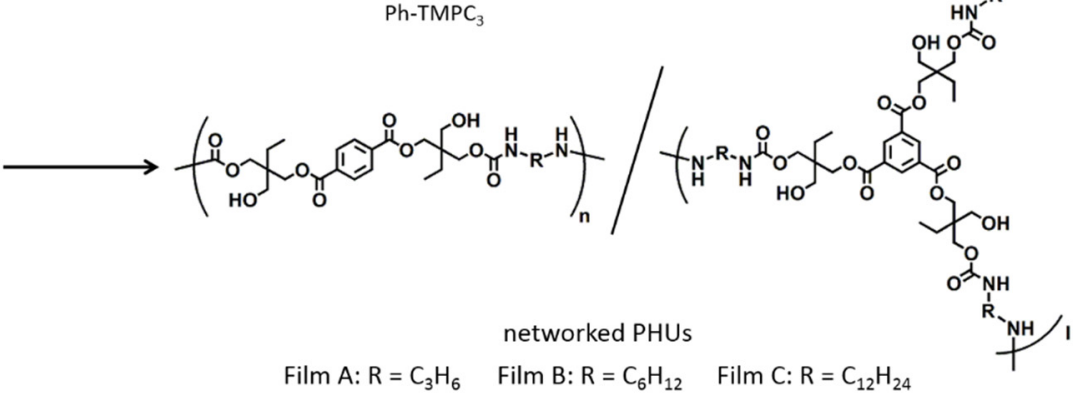

Scheme 3. a) Synthesis of linear PHUs (p(Ph-TMPC $2-\mathrm{R})$ ) by ring-opening polyaddition of Ph-TMPC $\mathrm{P}_{2}$ with conventional diamines $\left(\mathrm{R}=\mathrm{C}_{3} \mathrm{H}_{6}, \mathrm{C}_{6} \mathrm{H}_{12}, \mathrm{C}_{12} \mathrm{H}_{24}\right)$. b) Fabrication of networked PHUs by the copolymerization of

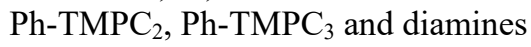

\section{Method}

\subsection{Reagents}

TMP, terephthaloyl chloride, dehydrated pyridine, trimethylamine and acetic anhydride were purchased from Wako Pure Chemical Co., Ltd. DPC, trimesoyl chloride, 1,3-diaminopropane $\left(\mathrm{C}_{3}\right)$, 1,6-diaminehexane $\left(\mathrm{C}_{6}\right)$ and 1,12-diaminododecane $\left(\mathrm{C}_{12}\right)$ were obtained from Tokyo Chemical Industry Co., Ltd. Other reagents and solvents were commercially obtained and used without any purification.

\subsection{Synthesis of TMPC-OH}

TMPC-OH was synthesized by the same procedure reported previously (Matsukizono, 2016). TMP $13.4 \mathrm{~g}$ (100 mmol) was added slowly to DPC $85.7 \mathrm{~g}(400 \mathrm{mmol})$ melted by heating at $140{ }^{\circ} \mathrm{C}$. After the mixture was stirred at $140{ }^{\circ} \mathrm{C}$ for $1-2$ days, the mixture was cooled to ambient temperature and then dissolved in EtOAc $(120 \mathrm{~mL})$ and hexane $(40 \mathrm{~mL})$. TMPC-OH was isolated by silica gel column chromatograph (eluent: n-hexane/EtOAc volume ratio of $1 / 3)$. The crude product was used for the following reactions without further purification. Yield: $56.6 \%$. ${ }^{1} \mathrm{H}$ NMR (400 MHz, $\left.\mathrm{CDCl}_{3}, \delta\right): 4.26\left(\mathrm{dxd}, 4 \mathrm{H}, J=70,11 \mathrm{~Hz},-\mathrm{CH}_{2}-\mathrm{OCOO}\right.$ - of cyclic carbonate), $3.67(\mathrm{~d}, 2 \mathrm{H}, J=4.8$ $\mathrm{Hz}, \mathrm{HO}-\mathrm{CH}_{2-}$ ), 2.77 (t, $\left.1 \mathrm{H}, J=5.4 \mathrm{~Hz}, \mathrm{HO}-\right), 1.51$ (q, $2 \mathrm{H}, J=7.6 \mathrm{~Hz}, \mathrm{CH}_{3}-\mathrm{CH}_{2^{-}}$), 0.93 (t, $3 \mathrm{H}, J=7.6 \mathrm{~Hz}^{-} \mathrm{CH}_{3}-$ ). ${ }^{13} \mathrm{C}$ NMR (400 MHz, DMSO-d 6 , $\left.\delta\right): 148.6(\mathrm{C}=\mathrm{O}), 72.8\left(-\mathrm{CH}_{2}-\mathrm{OCO}-\right), 59.8\left(\mathrm{HO}-\mathrm{CH}_{2}-\right), 35.8\left(C-\left(\mathrm{CH}_{2} \mathrm{O}\right)_{3}\right), 22.5$ $\left(\mathrm{CH}_{3}-\mathrm{CH}_{2}-\right), 7.6\left(\mathrm{CH}_{3}\right)$. IR (ATR): $\mathrm{v}=3408(\mathrm{~m} ; \mathrm{v}(\mathrm{O}-\mathrm{H})), 2968-2883\left(\mathrm{w} ; \mathrm{v}\left(\mathrm{CH}_{2}\right)\right), 1714(\mathrm{~s} ; \mathrm{v}(\mathrm{C}=\mathrm{O})), 1472-1409$ $\left(\mathrm{m} ; \delta\left(\mathrm{CH}_{2}\right)\right), 1180-1110 \mathrm{~cm}^{-1}(\mathrm{~s} ; \mathrm{v}(\mathrm{C}-\mathrm{O})$ of carbonate and alcohol).

\subsection{Synthesis of Ph-TMPC 2}

TMPC-OH $3.37 \mathrm{~g}(21.0 \mathrm{mmol})$ and terephthaloyl chloride $2.04 \mathrm{~g}(10.0 \mathrm{mmol})$ were individually dissolved in dehydrated THF $(15 \mathrm{~mL})$. To the TMPC-OH solution at $0{ }^{\circ} \mathrm{C}$, triethylamine $2.13 \mathrm{~g}(21.0 \mathrm{mmol})$ and the terephthaloyl chloride solution were slowly added and the mixture were stirred at ambient temperature for $14 \mathrm{~h}$. Resulting precipitates were collected by suction filtration and washed with THF. After dried, the precipitates were dissolved in $\mathrm{CH}_{2} \mathrm{Cl}_{2}(100 \mathrm{~mL})$ and then washed three times with distilled water $(100 \mathrm{~mL})$. The organic layer were dried over with anhydrous $\mathrm{Na}_{2} \mathrm{SO}_{4}$ and then concentrated. After drying under reduced pressure, $\mathrm{Ph}-\mathrm{TMPC}_{2}$ was obtained as a white solid. Yield: $3.09 \mathrm{~g}(68.5 \%) .{ }^{1} \mathrm{H} \mathrm{NMR}\left(400 \mathrm{MHz}, \mathrm{CDCl}_{3}, \delta\right): 8.10$ (s, 4.0H, phenyl), 4.43-4.30 $\left(\mathrm{m}, 12.0 \mathrm{H},-\mathrm{CH}_{2}-\mathrm{OC}(=\mathrm{O})-\right), 1.64\left(\mathrm{q}, 4.0 \mathrm{H}, J=7.6 \mathrm{~Hz}, \mathrm{CH}_{3}-\mathrm{CH}_{2}-\right), 1.02$ (t, $\left.6.0 \mathrm{H}, J=7.8 \mathrm{~Hz}, \mathrm{CH}_{3}-\right) .{ }^{13} \mathrm{C} \mathrm{NMR}(400$ $\left.\mathrm{MHz} \mathrm{CDCl}_{3}, \delta\right): 165.1$ (C=O of ester), 148.1 (C=O of carbonate), 133.5 (C1 of phenyl), 129.9 (C2 of phenyl), 72.7 
$\left(\mathrm{CH}_{2}-\mathrm{O}\right.$ of carbonate), $64.1\left(\mathrm{CH}_{2}-\mathrm{O}\right.$ of ester), $35.0\left(\mathrm{C}-\left(\mathrm{CH}_{2} \mathrm{O}\right)_{3}\right), 23.9\left(\mathrm{CH}_{3}-\mathrm{CH}_{2}\right), 7.5\left(\mathrm{CH}_{3}\right)$. IR (ATR): $\mathrm{v}=$ 2966-2885 (w; $\left.v\left(\mathrm{CH}_{2}\right)\right), 1756(\mathrm{~s} ; \mathrm{v}(\mathrm{C}=\mathrm{O}$ of ester $)), 1721 \mathrm{~cm}^{-1}(\mathrm{~s} ; \mathrm{v}(\mathrm{C}=\mathrm{O}$ of carbonate $))$

\subsection{Synthesis of $P h-T M P C_{3}$}

TMPC-OH $5.29 \mathrm{~g}(33.0 \mathrm{mmol})$ and dehydrated pyridine $2.61 \mathrm{~g}(33.0 \mathrm{mmol})$ were dissolved in dehydrated THF (50 $\mathrm{mL}$ ) and the solution was cooled to $0{ }^{\circ} \mathrm{C}$ in ice bath. To the solution was added slowly a dehydrated THF (30 mL) containing trimesoyl chloride $2.67 \mathrm{~g}(10.1 \mathrm{mmol})$ and the mixture was stirred at ambient temperature for $21 \mathrm{~h}$. Resulting precipitates were collected by suction filtration and washed with THF. After dried, the precipitates were dissolved in $\mathrm{CH}_{2} \mathrm{Cl}_{2}(100 \mathrm{~mL})$ and washed three times with distilled water $(100 \mathrm{~mL})$. After dried over with anhydrous $\mathrm{Na}_{2} \mathrm{SO}_{4}$, the organic layer was concentrated. The residues were purified by reprecipitation from acetone/methanol to give $\mathrm{Ph}_{-} \mathrm{TMPC}_{3}$ as a white solid. Yield: $3.73 \mathrm{~g}(58.6 \%) .{ }^{1} \mathrm{H} \mathrm{NMR}\left(400 \mathrm{MHz}, \mathrm{CDCl}_{3}, \delta\right): 8.81$ (s, 3.0H, phenyl), 4.52-4.31 (m, $18.0 \mathrm{H},-\mathrm{CH}_{2}-\mathrm{OC}(=\mathrm{O})$-), 1.64 (q, $\left.6.0 \mathrm{H}, J=7.6 \mathrm{~Hz}, \mathrm{CH}_{3}-\mathrm{CH}_{2}-\right), 1.02(\mathrm{t}, 9.0 \mathrm{H}, J=$ $\left.7.6 \mathrm{~Hz}, \mathrm{CH}_{3}-\right) .{ }^{13} \mathrm{C}$ NMR $\left(400 \mathrm{MHz}, \mathrm{CDCl}_{3}, \delta\right): 164.3(\mathrm{C}=\mathrm{O}$ of ester), $148.2(\mathrm{C}=\mathrm{O}$ of carbonate $), 135.2(\mathrm{C} 1$ of phenyl), 130.8 (C2 of phenyl), $72.9\left(\mathrm{CH}_{2}-\mathrm{O}\right.$ of carbonate), $65.3\left(\mathrm{CH}_{2}-\mathrm{O}\right.$ of ester $), 34.9\left(\mathrm{C}-\left(\mathrm{CH}_{2} \mathrm{O}\right)_{3}\right), 24.0$ $\left(\mathrm{CH}_{3}-\mathrm{CH}_{2}\right), 7.5\left(\mathrm{CH}_{3}\right)$. IR (ATR): $v=2973-2882\left(\mathrm{w} ; \mathrm{v}\left(\mathrm{CH}_{2}\right)\right), 1728 \mathrm{~cm}^{-1}(\mathrm{~s} ; \mathrm{v}(\mathrm{C}=\mathrm{O}$ of carbonate and ester $))$.

\subsection{Synthesis of linear PHUs}

\subsubsection{Synthesis of $\mathrm{p}\left(\mathrm{Ph}-\mathrm{TMPC}_{2}-\mathrm{C}_{3}\right)$}

To DMF (1.5 mL) containing Ph-TMPC $212 \mathrm{mg}(0.47 \mathrm{mmol})$ was added a DMF $(1.5 \mathrm{~mL})$ of $\mathrm{C}_{3} 32 \mathrm{mg}(0.43$ $\mathrm{mmol}$ ) at ambient temperature. The mixture was stirred at ambient temperature for $24 \mathrm{~h}$ and the fraction was analyzed by ${ }^{1} \mathrm{H}$ NMR spectroscopy and SEC measurements. After that, the mixture was added in distilled water $(100 \mathrm{~mL})$ and then the resulting precipitates were washed thoroughly with distilled water. The precipitates were collected by dissolving in acetone and drying under reduced pressure to obtain $\mathrm{p}\left(\mathrm{Ph}-\mathrm{TMPC}_{2}-\mathrm{C}_{3}\right)$ having TMPC terminals as colorless liquids. Yield: $109 \mathrm{mg}(44.7 \%) .{ }^{1} \mathrm{H} \mathrm{NMR}\left(400 \mathrm{MHz}, \mathrm{CDCl}_{3}, \delta\right): 8.11-8.05$ (m, 4.3H, phenyl), 7.05 (br, $1.9 \mathrm{H}, \mathrm{NH}), 4.68(\mathrm{br}, 2.0 \mathrm{H}, \mathrm{OH}), 4.42-4.31\left(\mathrm{~m}, 1.4 \mathrm{H},-\mathrm{CH}_{2}-\mathrm{OC}(=\mathrm{O})\right.$ - of terminal cyclic carbonates), 4.12 $\left(\mathrm{s}, 4.0 \mathrm{H},-\mathrm{CH}_{2}-\mathrm{OC}(=\mathrm{O})-\mathrm{Ph}\right), 3.92\left(\mathrm{~s}, 3.8 \mathrm{H},-\mathrm{CH}_{2}-\mathrm{OC}(=\mathrm{O})-\mathrm{NH}\right), 3.37\left(\mathrm{~s}, 3.9 \mathrm{H},-\mathrm{CH}_{2}-\mathrm{OH}\right), 3.03-2.87(\mathrm{~m}, 4.4 \mathrm{H}$, $\left.\mathrm{NH}-\mathrm{CH}_{2}-\mathrm{CH}_{2}-\right), 1.54-1.37\left(\mathrm{~m}, 6.4 \mathrm{H}, \mathrm{CH}_{3}-\mathrm{CH}_{2}\right.$ and $\left.\mathrm{NH}-\mathrm{CH}_{2}-\mathrm{CH}_{2}-\right), 0.87-0.81$ (m, 6.6H, $\mathrm{CH}_{3}-$ ). IR (ATR): $\mathrm{v}=$ $3360(\mathrm{w} ; \mathrm{v}(\mathrm{OH})), 2963-2883\left(\mathrm{w} ; \mathrm{v}\left(\mathrm{CH}_{2}\right)\right), 1713\left(\mathrm{~s} ; \mathrm{v}\left(\mathrm{C}=\mathrm{O}\right.\right.$ of carbonate and ester)), $1268 \mathrm{~cm}^{-1}(\mathrm{~s} ; \mathrm{v}(\mathrm{C}-\mathrm{O}))$.

\subsubsection{Synthesis of $\mathrm{p}\left(\mathrm{Ph}-\mathrm{TMPC}_{2}-\mathrm{C}_{6}\right)$}

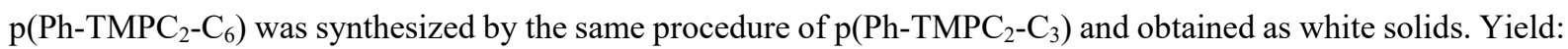
91.8\%. ${ }^{1} \mathrm{H}$ NMR (400 MHz, DMSO-d 6 , $\delta$ ): 8.09-8.05 (m, 4.5H, phenyl), 7.04 (br, 1.8H, NH), 4.73-4.68 (br, 1.9H, $\mathrm{OH}), 4.42-4.31\left(\mathrm{~m}, 1.5 \mathrm{H},-\mathrm{CH}_{2}-\mathrm{OC}(=\mathrm{O})\right.$ - of terminal cyclic carbonates), $4.12\left(\mathrm{~s}, 4.0 \mathrm{H},-\mathrm{CH}_{2}-\mathrm{OC}(=\mathrm{O})-\mathrm{Ph}\right), 3.92(\mathrm{~s}$, $\left.3.7 \mathrm{H},-\mathrm{CH}_{2}-\mathrm{OC}(=\mathrm{O})-\mathrm{NH}\right), 3.37\left(\mathrm{~s}, 3.9 \mathrm{H},-\mathrm{CH}_{2}-\mathrm{OH}\right), 3.00-2.85\left(\mathrm{~m}, 4.0 \mathrm{H}, \mathrm{NH}-\mathrm{CH}_{2}-\mathrm{CH}_{2}-\right), 1.51-1.11(\mathrm{~m}, 12.4 \mathrm{H}$, $\mathrm{CH}_{3}-\mathrm{CH}_{2-}$ and $\left.\mathrm{NH}-\mathrm{CH}_{2}-\left(\mathrm{CH}_{2}\right)_{4}-\right), 0.87-0.81\left(\mathrm{~m}, 6.6 \mathrm{H}, \mathrm{CH}_{3}-\right.$ ). IR (ATR): $\mathrm{v}=3339$ (w; $\mathrm{v}(\mathrm{OH})$ ), 2962-2881 (w; $\left.v\left(\mathrm{CH}_{2}\right)\right), 1700(\mathrm{~s} ; \mathrm{v}(\mathrm{C}=\mathrm{O}$ of carbonate and ester $)), 1246 \mathrm{~cm}^{-1}(\mathrm{~s} ; \mathrm{v}(\mathrm{C}-\mathrm{O}))$.

\subsubsection{Synthesis of $\mathrm{p}\left(\mathrm{Ph}-\mathrm{TMPC}_{2}-\mathrm{C}_{12}\right)$}

$\mathrm{p}\left(\mathrm{Ph}-\mathrm{TMPC}_{2}-\mathrm{C}_{12}\right)$ was synthesized by the same procedure of $\mathrm{p}\left(\mathrm{Ph}-\mathrm{TMPC}_{2}-\mathrm{C}_{3}\right)$ and obtained as white solids. Yield: 69.3\%. ${ }^{1} \mathrm{H}$ NMR (400 MHz, DMSO-d $\mathrm{d}_{6}, \delta$ ): 8.09-8.05 (m, 4.4H, phenyl), 7.03 (br, 1.8H, NH), 4.73-4.67 (br, 1.9H, $\mathrm{OH}), 4.42-4.31\left(\mathrm{~m}, 1.5 \mathrm{H},-\mathrm{CH}_{2}-\mathrm{OC}(=\mathrm{O})\right.$ - of terminal cyclic carbonates), $4.12\left(\mathrm{~s}, 4.0 \mathrm{H},-\mathrm{CH}_{2}-\mathrm{OC}(=\mathrm{O})-\mathrm{Ph}\right), 3.92(\mathrm{~s}$, $\left.3.8 \mathrm{H},-\mathrm{CH}_{2}-\mathrm{OC}(=\mathrm{O})-\mathrm{NH}\right), 3.37\left(\mathrm{~s}, 3.9 \mathrm{H},-\mathrm{CH}_{2}-\mathrm{OH}\right), 3.01-2.85\left(\mathrm{~m}, 4.0 \mathrm{H}, \mathrm{NH}-\mathrm{CH}_{2}-\mathrm{CH}_{2}-\right), 1.51-1.27(\mathrm{~m}, 8.6 \mathrm{H}$, $\mathrm{CH}_{3}-\mathrm{CH}_{2}$ - and $\left.\mathrm{NH}-\mathrm{CH}_{2}-\mathrm{CH}_{2}-\right), 1.13\left(\mathrm{~s}, 16.0 \mathrm{H}, \mathrm{NH}-\left(\mathrm{CH}_{2}\right)_{2}-\left(\mathrm{CH}_{2}\right)_{8}\right)^{-}, 0.87-0.80\left(\mathrm{~m}, 6.6 \mathrm{H}, \mathrm{CH}_{3}{ }^{-}\right)$. IR (ATR): $v=$ $3345(\mathrm{w} ; \mathrm{v}(\mathrm{OH})), 2964-2881\left(\mathrm{w} ; \mathrm{v}\left(\mathrm{CH}_{2}\right)\right), 1698(\mathrm{~s} ; \mathrm{v}(\mathrm{C}=\mathrm{O}$ of carbonate and ester $)), 1243 \mathrm{~cm}^{-1}(\mathrm{~s} ; \mathrm{v}(\mathrm{C}-\mathrm{O}))$.

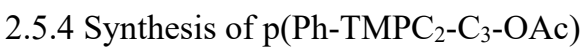

$\mathrm{p}\left(\mathrm{Ph}-\mathrm{TMPC}_{2}-\mathrm{C}_{3}\right)$ was synthesized by the reaction of $\mathrm{Ph}-\mathrm{TMPC}_{2} 202 \mathrm{mg}(0.45 \mathrm{mmol}, 1.1$ equiv. $)$ and $\mathrm{C}_{3} 30 \mathrm{mg}$ $\left(0.41 \mathrm{mmol}, 1.0\right.$ equiv.) in DMF $(2.0 \mathrm{~mL})$. Without purification, $\mathrm{p}\left(\mathrm{Ph}-\mathrm{TMPC}_{2}-\mathrm{C}_{3}-\mathrm{OAc}\right)$ was synthesized. To the DMF solution of $\mathrm{p}\left(\mathrm{Ph}-\mathrm{TMPC}_{2}-\mathrm{C}_{3}\right)$, acetic anhydride $315 \mathrm{mg}(3.09 \mathrm{mmol})$ and pyridine $245 \mathrm{mg}(3.10 \mathrm{mmol})$ were added at ambient temperature and the mixture was stirred at $40{ }^{\circ} \mathrm{C}$ for $41 \mathrm{~h}$. After DMF was removed, the yellow residues were dissolved in $\mathrm{CH}_{2} \mathrm{Cl}_{2}(100 \mathrm{~mL})$ and then washed three times with distilled water $(100 \mathrm{~mL})$. After drying with anhydrous $\mathrm{Na}_{2} \mathrm{SO}_{4}, \mathrm{CH}_{2} \mathrm{Cl}_{2}$ was evaporated. After the yellow residues were dried under reduced pressure, $\mathrm{p}\left(\mathrm{Ph}-\mathrm{TMPC}_{2}-\mathrm{C}_{3}-\mathrm{OAc}\right)$ was obtained as pale yellow solids. Yield: $253 \mathrm{mg}(95.0 \%) .{ }^{1} \mathrm{H} \mathrm{NMR}(400 \mathrm{MHz}$, $\left.\mathrm{CDCl}_{3}, \delta\right): 8.08\left(\mathrm{~m}, 4.4 \mathrm{H}\right.$, phenyl), $5.23(\mathrm{br}, 2.1 \mathrm{H}, \mathrm{NH}), 4.44-4.41\left(\mathrm{~m}, 1.2 \mathrm{H},-\mathrm{CH}_{2}-\mathrm{OC}(=\mathrm{O})-\right.$ of terminal cyclic carbonates), 4.32-4.11 (m, 11.6H, $-\mathrm{CH}_{2}-\mathrm{OC}(=\mathrm{O})$ ), 3.27-3.12 (s, 4.0H, $\left.\mathrm{NH}-\mathrm{CH}_{2}-\mathrm{CH}_{2}-\right), 2.06$ (s, 5.8H, $\mathrm{CH}_{3}-(\mathrm{C}=\mathrm{O})$ ), 1.67-1.57 (m, 6.4H, $\mathrm{CH}_{3}-\mathrm{CH}_{2}$ - and $\mathrm{NH}-\mathrm{CH}_{2}-\mathrm{CH}_{2}-$ ), $1.04-0.93$ (m, 6.6H, $\mathrm{CH}_{3}-\mathrm{CH}_{2}-$ ). IR (ATR): $\mathrm{v}=3367$ (w; $v(\mathrm{OH}$ of residual hydroxyl group or adsorbed water $)), 2965-2880\left(\mathrm{w} ; \mathrm{v}\left(\mathrm{CH}_{2}\right)\right), 1720(\mathrm{~s} ; \mathrm{v}(\mathrm{C}=\mathrm{O}$ of carbonate and ester)), $1241 \mathrm{~cm}^{-1}(\mathrm{~s} ; \mathrm{v}(\mathrm{C}-\mathrm{O}))$. 


\subsubsection{Synthesis of $\mathrm{p}\left(\mathrm{Ph}-\mathrm{TMPC}_{2}-\mathrm{C}_{3}\right)$ '}

A DMF solution $(1.0 \mathrm{~mL})$ of $\mathrm{C}_{3} 163 \mathrm{mg}(2.2 \mathrm{mmol}, 1.1$ equiv. $)$ was added to a DMF solution $(2.0 \mathrm{~mL})$ of $\mathrm{Ph}-\mathrm{TMPC}_{2} 901 \mathrm{mg}(2.0 \mathrm{mmol})$ at $70{ }^{\circ} \mathrm{C}$. At the temperature, the mixture was stirred for $17 \mathrm{~h}$ and then cooled to ambient temperature. After concentrated, the mixture was added to distilled water $(200 \mathrm{~mL})$ and the precipitates were washed with distilled water. After the precipitates were dissolved in acetone, the solution was concentrated and then dried under reduced pressure to give $\mathrm{p}\left(\mathrm{Ph}-\mathrm{TMPC}_{2}-\mathrm{C}_{3}\right)$ ' as white solids. Yield: $95.2 \%$. ${ }^{1} \mathrm{H} \mathrm{NMR}(400 \mathrm{MHz}$, $\left.\mathrm{CDCl}_{3}, \delta\right): 8.05\left(\mathrm{~s}, 4.1 \mathrm{H}\right.$, phenyl), 7.05-6.72 (m, 2.0H, NH), $4.68(\mathrm{br}, 1.9 \mathrm{H}, \mathrm{OH}), 4.12\left(\mathrm{~s}, 4.0 \mathrm{H},-\mathrm{CH}_{2}-\mathrm{OC}(=\mathrm{O})-\mathrm{Ph}\right)$, $3.92\left(\mathrm{~s}, 4.0 \mathrm{H},-\mathrm{CH}_{2}-\mathrm{OC}(=\mathrm{O})-\mathrm{NH}\right), 3.37\left(\mathrm{~s}, 4.0 \mathrm{H},-\mathrm{CH}_{2}-\mathrm{OH}\right), 3.01-2.85\left(\mathrm{~m}, 4.3 \mathrm{H}, \mathrm{NH}-\mathrm{CH}_{2}-\mathrm{CH}_{2}-\right), 1.55-1.37(\mathrm{~m}$, $6.2 \mathrm{H}, \mathrm{CH}_{3}-\mathrm{CH}_{2}$ - and $\left.\mathrm{NH}-\mathrm{CH}_{2}-\mathrm{CH}_{2}-\right), 0.81\left(\mathrm{t}, 6.1 \mathrm{H}, J=7.2 \mathrm{~Hz}, \mathrm{CH}_{3}-\right.$ ). IR (ATR): $v=3364$ (w; $v\left(\mathrm{OH}\right.$ and $\left.\mathrm{NH}_{2}\right)$ ), 2964-2881 (w; $\left.v\left(\mathrm{CH}_{2}\right)\right), 1698(\mathrm{~s} ; \mathrm{v}(\mathrm{C}=\mathrm{O}$ of carbonate and ester $)), 1243 \mathrm{~cm}^{-1}(\mathrm{~s} ; \mathrm{v}(\mathrm{C}-\mathrm{O}))$.

\subsection{Fabrication of Networked PHU Films}

$\mathrm{Ph}-\mathrm{TMPC}_{2}$ and $\mathrm{Ph}-\mathrm{TMPC}_{3}$ were dissolved in DMF $(1 \mathrm{~mL})$ at $70{ }^{\circ} \mathrm{C}$ to prepare the $\mathrm{Ph}-\mathrm{TMPC}_{2} / \mathrm{Ph}-\mathrm{TMPC}_{3}$ solution at different molar ratios $\left(5-20 \mathrm{~mol} \%\right.$ of $\mathrm{Ph}-\mathrm{TMPC}_{3}$ with respect to the total carbonate monomers $\left(\mathrm{Ph}-\mathrm{TMPC}_{2}+\right.$ $\left.\left.\mathrm{Ph}-\mathrm{TMPC}_{3}\right),[\mathrm{TMPC}]=0.5 \mathrm{M}\right)$. To the solutions, $\mathrm{C}_{3}$ dissolved in $\mathrm{DMF}\left(0.5 \mathrm{~mL},\left[\mathrm{C}_{3}\right]=0.25 \mathrm{M}\right)$ was added and then the mixed solutions (TMPC/NH$=1.0$ ) were stirred at $70{ }^{\circ} \mathrm{C}$ for within $5 \mathrm{~min}$. After that, the solutions were poured in glass petri-dishes with $6.0 \mathrm{~cm}$ in diameter and allowed to stand at $60^{\circ} \mathrm{C}$ overnight. The resulting films were carefully removed and immersed in distilled water for purification. After drying, the networked PHU films (Film A) were obtained. Similarly, Film B and Film C were prepared using $20 \mathrm{~mol} \% \mathrm{Ph}-\mathrm{TMPC}_{3}$ and $\mathrm{C}_{6}$ or $\mathrm{C}_{12}$, respectively.

\subsection{Measurements}

${ }^{1} \mathrm{H}$ and ${ }^{13} \mathrm{C}$ NMR spectra were recorded with a JEOL ECS-400 NMR spectrometer operating at $400 \mathrm{MHz}$ using a tetramethylsilane (TMS) as an internal reference. FT-IR spectroscopy was conducted with a Thermo Fisher Scientific Nicolet iS10 equipped with an ATR instrument. SEC were performed with a Tosoh HLC-8320GPC using DMF as eluents operating at a flow rate of $0.5 \mathrm{~mL} \mathrm{~min}^{-1}$. Number averaged molecular weight $\left(M_{\mathrm{n}}\right)$, Weight averaged molecular weight $\left(M_{\mathrm{w}}\right)$ and polydispersity $\left(M_{\mathrm{w}} / M_{\mathrm{n}}\right)$ were determined from SCE traces using polystyrene standards. PHU films were fabricated by gradual drying of monomer solutions under ambient atmosphere using a Sanso Vacuum Drying Oven SVD10P (width, $20 \mathrm{~cm}$; depth, $25 \mathrm{~cm}$; height, $20 \mathrm{~cm}$ ). TGA was carried out with a TG/DTA 6200 (Seiko Instrument Inc.) at a heating rate of $10^{\circ} \mathrm{C} \mathrm{min}^{-1}$ under nitrogen gas at a flow rate of $200 \mathrm{~mL}$ $\mathrm{min}^{-1}$. UV/Vis.-NIR spectra were recorded on a Jasco V570 UV/VIS/NIR spectrophotometer equipped with Pbs power supply instruments. Stress-strain curves were measured with a Shimazu EZ Test EZ-LX with an operation rate of $50 \mathrm{~mm} \mathrm{~min}^{-1}$. Young's modulus $(E)$, stress at yield point $\left(\sigma_{\text {yield }}\right)$, stress at break point $\left(\sigma_{\text {break }}\right)$ and strain at break point $\left(\varepsilon_{\text {break }}\right)$ of the films were analyzed with a TRAPEZIUM X software. The tensile tests were performed 1-3 times and then mechanical parameters were averaged.

\section{Results and Discussion}

\subsection{Synthesis of bi- and Trifunctional 6-CCs Based on TMPC}

The reaction of TMP and DPC gives mainly three types of different structured TMPCs (Matsukizono, 2016). These TMPCs can be to some extent individually produced by the modulation of synthetic conditions. Longer reaction time leads to the formation of TMPC-OCOPh and TMPC-dimer, while shorter reaction periods afford dominantly TMPC-OH. In this case, TMP was reacted with 4 equiv. of DPC at $140{ }^{\circ} \mathrm{C}$ for $1-2$ days and consequently, TMPC-OH was obtained in $56.6 \%$ yield after purification by column chromatography. The ${ }^{1} \mathrm{H}$ and ${ }^{13} \mathrm{C}$ NMR spectra of TMPC-OH are shown in Figure S1 in the appendix section.

The bifunctional TMP-based cyclic carbonate $\left(\mathrm{Ph}-\mathrm{TMPC}_{2}\right)$ was synthesized by the simple reaction of TMPC-OH, terephthaloyl chloride and triethylamine in anhydrous THF. While the reaction proceeded, $\mathrm{Ph}-\mathrm{TMPC}_{2}$ and triethylamine hydrochloride precipitated. After washing with distilled water followed by methanol, white solids were isolated in $68.5 \%$ yield. The ${ }^{1} \mathrm{H}$ NMR spectrum of the solids is shown in Figure 1. The signal at $3.6 \mathrm{ppm}$ assigned to methylene protons adjacent to a hydroxyl group completely disappears, while the singlet signal ascribed to methylene protons neighboring to an ester bond newly appears at $4.4 \mathrm{ppm}$. The singlet signal at 8.1 ppm originates from benzene protons, the integral ratio of which is ca. 4.0 and equals to the theoretical value. In addition, the ${ }^{13} \mathrm{C}$ NMR spectrum of the solids gives a signal at $165 \mathrm{ppm}$ originating from ester carbons and signals at 133 and $130 \mathrm{ppm}$ assigned to benzene carbons (Figure S2). FT-IR spectrum of the solids exhibits no absorption at around $3500 \mathrm{~cm}^{-1}$ based on hydroxyl groups, while the characteristic absorption of ester bonds appears at 1756 $\mathrm{cm}^{-1}$ (Figure S3). These results clearly indicate that $\mathrm{Ph}-\mathrm{TMPC}_{2}$ is obtained as white solids. Similarly, $\mathrm{Ph}-\mathrm{TMPC}_{3}$ was synthesized from TMPC-OH and trimesoyl chloride and isolated as white solids in $58.6 \%$ yield. The ${ }^{1} \mathrm{H} N M R$ 
spectrum of $\mathrm{Ph}_{-} \mathrm{TMPC}_{3}$ exhibits the signals assigned to the benzene protons at $8.81 \mathrm{ppm}$ and methylene protons adjacent to ester bonds at $4.49 \mathrm{ppm}$ (Figure 2). In FT-IR spectrum of Ph-TMPC 3 , the streching vibration of hydroxyl groups disappears and ${ }^{13} \mathrm{C}$ NMR spectrum of $\mathrm{Ph}-\mathrm{TMPC}_{3}$ shows the signals assigned to carbonyl carbons of ester bonds and benzene carbons (Figure S3 and S4), indicating the formation and purification of $\mathrm{Ph}_{-} \mathrm{TMPC}_{3}$.

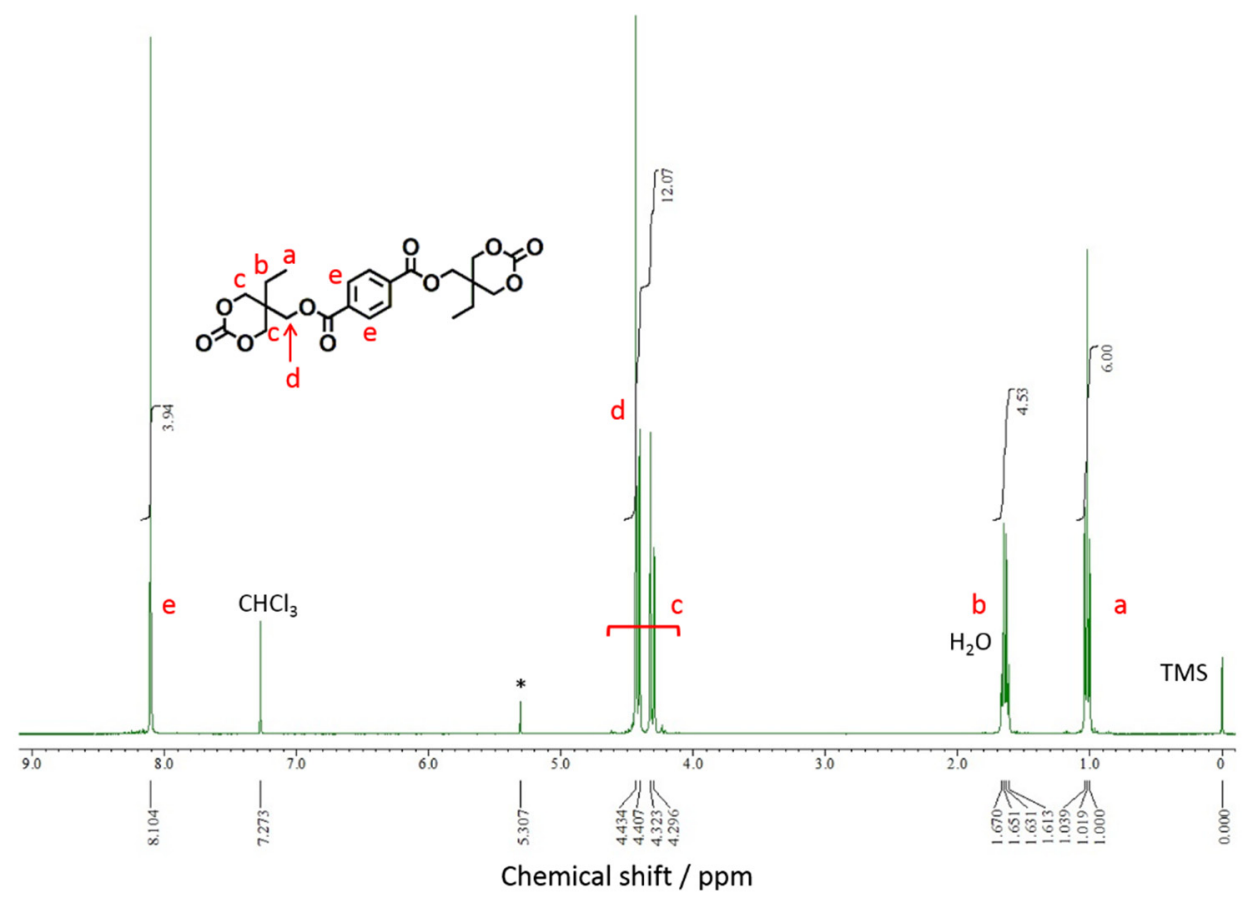

Figure $1 .{ }^{1} \mathrm{H}$ NMR spectrum of $\mathrm{Ph}-\mathrm{TMPC}_{2}$ in $\mathrm{CDCl}_{3}$ containing $0.03 \mathrm{v} / \mathrm{v} \%$ of TMS. An asterisk denotes residual $\mathrm{CH}_{2} \mathrm{Cl}_{2}$ used for purification

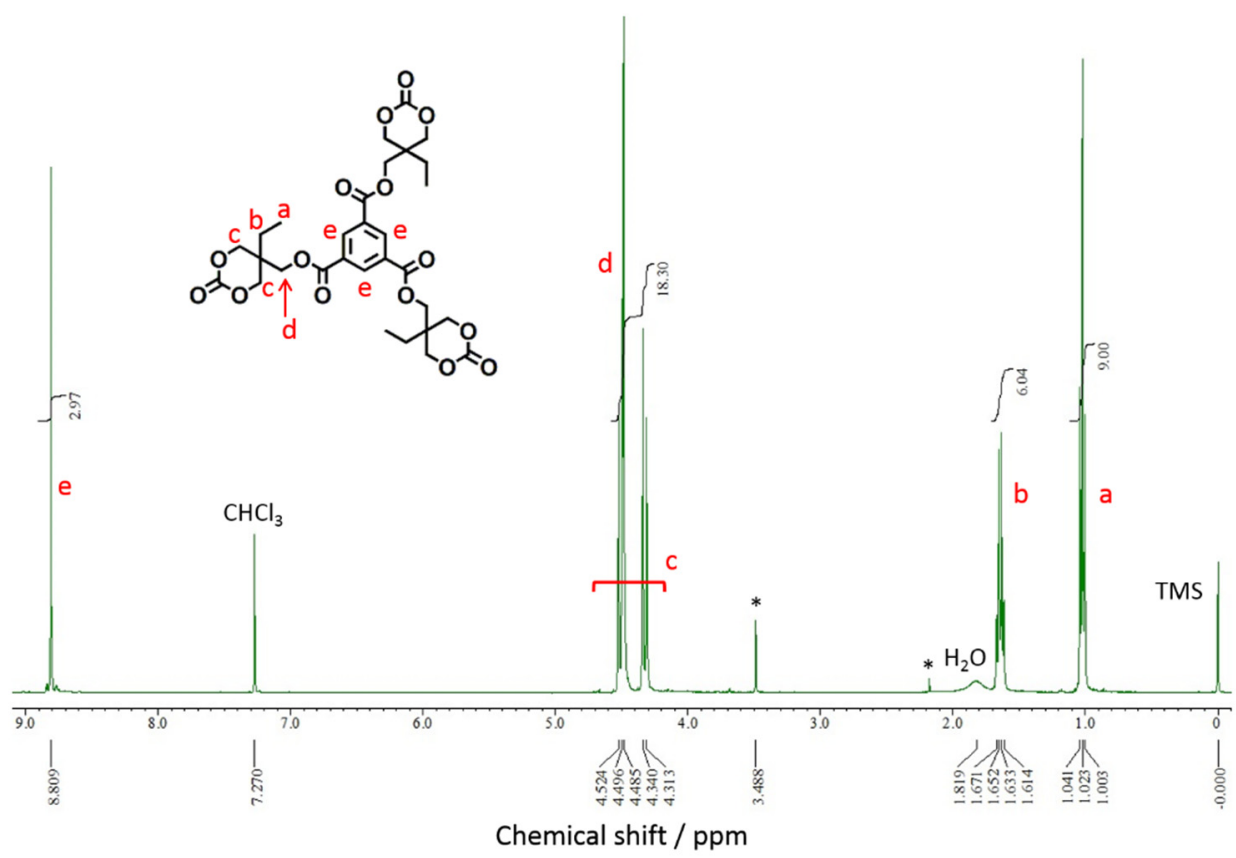

Figure 2. ${ }^{1} \mathrm{H}$ NMR spectrum of $\mathrm{Ph}-\mathrm{TMPC}_{3}$ in $\mathrm{CDCl}_{3}$ containing $0.03 \mathrm{v} / \mathrm{v} \%$ of TMS. Asterisks mean residual $\mathrm{MeOH}$ and acetone used for purification 
a)

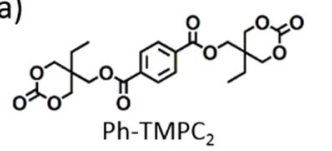

(1.1 equiv.)
$\mathrm{H}_{2} \mathrm{~N}-\mathrm{R}-\mathrm{NH}_{2}$

$(1.0$ equiv.)

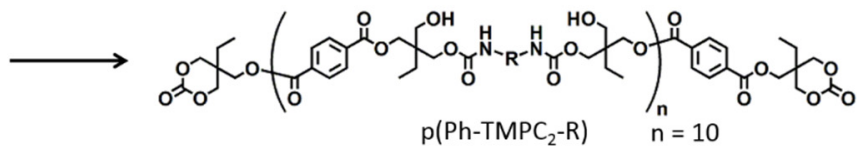

$\downarrow \begin{aligned} & \text { acetic anhydride, } \\ & \text { pyridine }\end{aligned}$

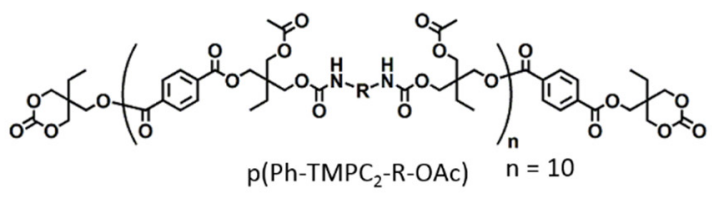

b)

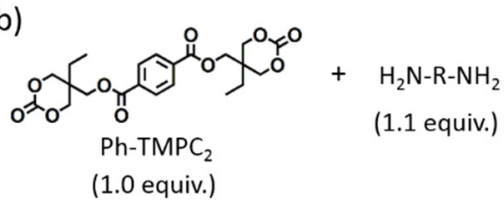

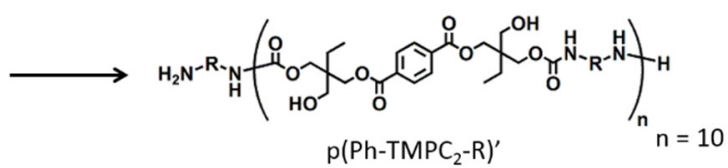

$\mathrm{p}\left(\mathrm{Ph}^{\mathrm{TMPC}} \mathrm{TM}_{2}-\mathrm{R}\right)^{\prime}$

Scheme 4. Synthesis of PHUs with different terminal structures from Ph-TMPC $\mathrm{C}_{2}$ and diamine $\left(\mathrm{R}=\mathrm{C}_{3} \mathrm{H}_{6}, \mathrm{C}_{6} \mathrm{H}_{12}\right.$ or $\left.\mathrm{C}_{12} \mathrm{H}_{24}\right)$ at different $\mathrm{Ph}-\mathrm{TMPC}_{2} /$ diamine feed ratios. a) PHUs with cyclic carbonate terminals ( $\mathrm{p}\left(\mathrm{Ph}-\mathrm{TMPC}_{2}-\mathrm{R}\right)$ ) by the polyaddition of 1.1 equiv. of $\mathrm{Ph}-\mathrm{TMPC}_{2}$ and 1.0 equiv. of diamine and acetylated PHUs with same terminal structures ( $\left.\mathrm{p}\left(\mathrm{Ph}-\mathrm{TMPC}_{2}-\mathrm{R}-\mathrm{OAc}\right)\right)$ after acetylation. b) PHUs with amine terminals $\left(\mathrm{p}\left(\mathrm{Ph}-\mathrm{TMPC}_{2}-\mathrm{R}\right)\right.$ ') by the polyaddition of 1.0 equiv. of $\mathrm{Ph}-\mathrm{TMPC}_{2}$ and 1.1 equiv. of diamine

\subsection{Synthesis and Characterization of PHUs Synthesized from Ph-TMPC $C_{2}$ and Conventional diamines}

Before the fabrication of networked PHUs, we investigated whether the ring-opening polyaddition of $\mathrm{Ph}-\mathrm{TMPC}_{2}$ and diamines proceeds to form linear PHUs with well-controlled structures or not. The reaction of $\mathrm{Ph}-\mathrm{TMPC}_{2}$ with an equivalent amount of diamine, in which $\mathrm{Ph}-\mathrm{TMPC}_{2} /$ diamine feed ratio is 1.0 , leads to the formation of long-chained PHUs, however, the chain ends of the PHUs are unclear. On the other hand, slight different $\mathrm{Ph}-\mathrm{TMPC}_{2} /$ diamine feed ratios provide shorter-chained PHUs with cyclic carbonate or amine terminals (Scheme 4). In this paper, we preferred the synthesis of shorter-chained PHUs with well-controlled terminal structures to the formation of longer-chained PHUs.

At first, we carried out the polyaddition of 1.1 equiv. of $\mathrm{Ph}-\mathrm{TMPC}_{2}$ with 1.0 equiv. of $\mathrm{C}_{3}$ in $\mathrm{DMF}$ at $70^{\circ} \mathrm{C}$ for 1 day. The reaction mixture was analyzed by ${ }^{1} \mathrm{H}$ NMR spectroscopy and SEC measurements. The conversion of $\mathrm{Ph}-\mathrm{TMPC}_{2}$ was determined by the change in the integral ratio of signals at 4.4-4.3 ppm assigned to methylene protons adjacent to ester and carbonate bonds. In actual, the integral ratio is 1.62 , which includes the integral ratio of a slightly excess amount ( 0.1 equiv.) of $\mathrm{Ph}^{-\mathrm{TMPC}_{2}}$ as well as unreacted ones, and then the conversion of $\mathrm{Ph}-\mathrm{TMPC}_{2}$ is calculated to be $96.5 \%$. After the reaction mixture was added in distilled water, the resulting precipitate was analyzed by ${ }^{1} \mathrm{H}$ NMR, FT-IR spectroscopy and SEC measurement. Figure 3 exhibits ${ }^{1} \mathrm{H}$ NMR spectrum of the precipitate. The signals at 4.4-4.3 ppm decrease and three signals at 4.1, 3.9 and $3.4 \mathrm{ppm}$ newly appear. These signals are ascribed to methylene protons adjacent to ester, urethane and hydroxyl groups, respectively. In addition, the signals based on $\mathrm{NH}$ and $\mathrm{OH}$ bonds appear at 7.0-6.7 and $4.7 \mathrm{ppm}$, respectively. The conversion after purification is calculated to be $98.0 \%$, which is slightly higher than that before purification. This is due to the purification treatment. On the other hand, $M_{\mathrm{n}}$ and $M_{\mathrm{w}} / M_{\mathrm{n}}$ values of the precipitate calculated by its SEC trace are 4,400 $\mathrm{g} \mathrm{mol}^{-1}$ and 2.11, respectively. These values are close to their theoretical ones $\left(M_{\mathrm{n}}=4,100 \mathrm{~g}\right.$ $\mathrm{mol}^{-1}, M_{\mathrm{w}} / M_{\mathrm{n}}=2.00$ ). These results apparently indicate that the reaction of $\mathrm{Ph}-\mathrm{TMPC}_{2}$ with $\mathrm{C}_{3}$ proceeds efficiently to form PHUs with cyclic carbonate terminals without the cleavage of ester bonds. When the synthesis of PHUs from $\mathrm{Ph}-\mathrm{TMPC}_{2}$ and $\mathrm{C}_{3}$ was performed at lower temperature, the PHUs with similar $M_{\mathrm{n}}$ and $M_{\mathrm{w}} / M_{\mathrm{n}}$ values were obtained (data are not shown). 


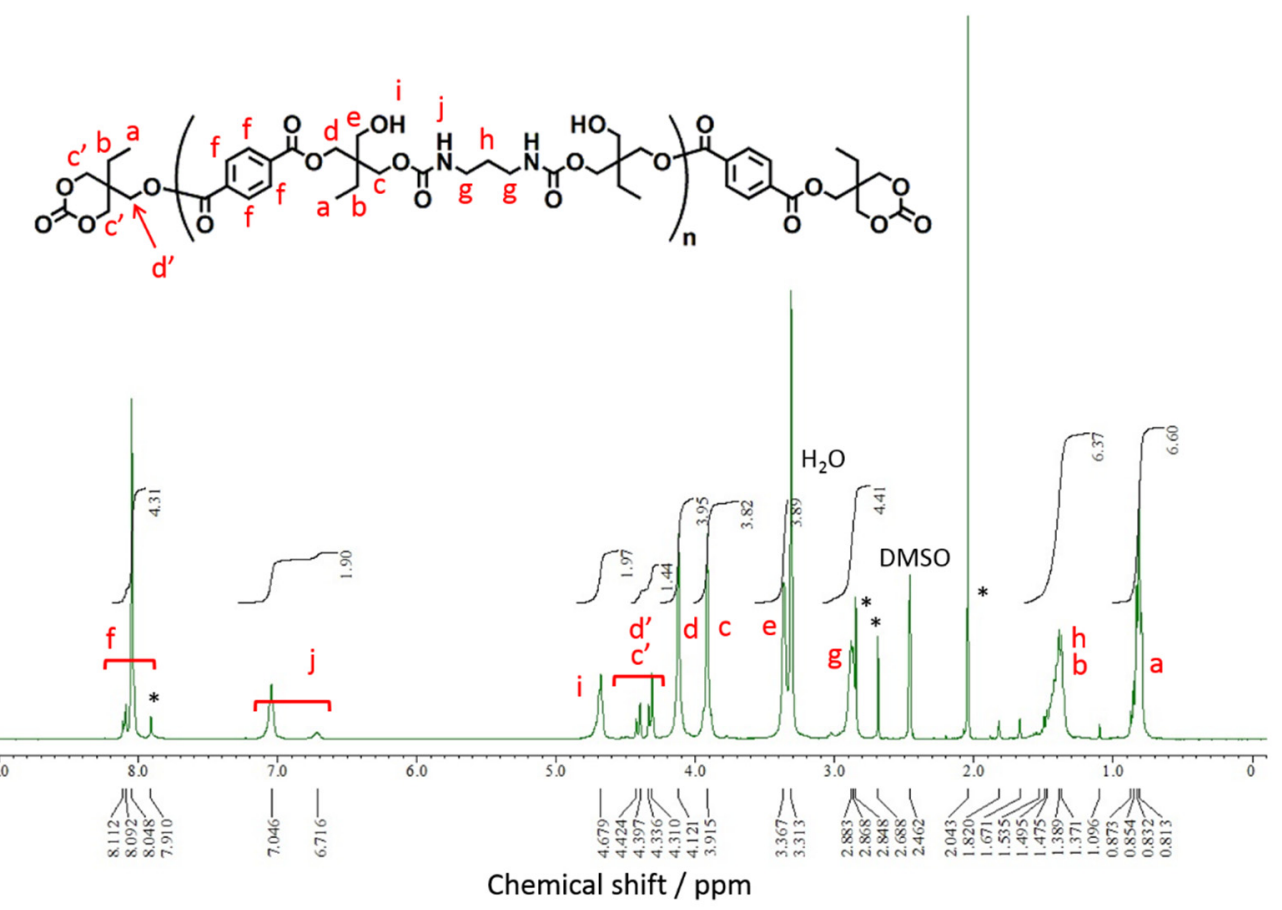

Figure 3. ${ }^{1} \mathrm{H}$ NMR spectrum of $\mathrm{p}\left(\mathrm{Ph}-\mathrm{TMPC}_{2}-\mathrm{C}_{3}\right)$ in DMSO- $\mathrm{d}_{6}$. Asterisks mean residual DMF and acetone

Table 1. Characterization of PHUs synthesized from $\mathrm{Ph}-\mathrm{TMPC}_{2}$ and diamines with different methylene spacers

\begin{tabular}{ccccccc}
\hline Entry & PHUs & $r^{\mathrm{a}}$ & Conv. $/ \%^{\mathrm{b}}$ & $M_{\mathrm{n}, \text { theor }} / \mathrm{g} \mathrm{mol}^{-1 \mathrm{c}}$ & $M_{\mathrm{n}} / \mathrm{g} \mathrm{mol}^{-1 \mathrm{~d}}$ & $M_{\mathrm{w}} / M_{\mathrm{n}}{ }^{\mathrm{d}}$ \\
\hline 1 & $\mathrm{p}\left(\mathrm{pH}-\mathrm{TMPC}_{2}-\mathrm{C}_{3}\right)$ & 1.1 & 98.0 & 4,100 & 4,400 & 2.11 \\
2 & $\mathrm{p}\left(\mathrm{pH}-\mathrm{TMPC}_{2}-\mathrm{C}_{6}\right)$ & 1.1 & 99.0 & 4,300 & 3,600 & 2.07 \\
3 & $\mathrm{p}\left(\mathrm{pH}-\mathrm{TMPC}_{2}-\mathrm{C}_{12}\right)$ & 1.1 & 97.6 & 4,700 & 5,000 & 2.13 \\
4 & $\mathrm{p}\left(\mathrm{pH}-\mathrm{TMPC}_{2}-\mathrm{C}_{3}-\mathrm{OAc}\right)$ & 1.1 & $>99.9$ & 7,000 & 3,400 & 1.92 \\
5 & $\mathrm{p}\left(\mathrm{pH}_{-} \mathrm{TMPC}_{2}-\mathrm{C}_{3}\right)$ & 0.91 & $>99.9$ & 5,300 & 5,300 & 2.19 \\
\hline
\end{tabular}

${ }^{\text {a }} \mathrm{Ph}-\mathrm{TMPC}_{2} /$ diamine feed ratio. ${ }^{\mathrm{b}}$ Reactivity of $\mathrm{Ph}-\mathrm{TMPC}_{2}$ calculated by ${ }^{1} \mathrm{H}$ NMR spectroscopy. ${ }^{\mathrm{c}}$ Determined using the conversion values. ${ }^{\mathrm{d}}$ Determined by SEC traces using polystyrene standards.

Similarly, using $\mathrm{C}_{6}$ or $\mathrm{C}_{12}$ instead of $\mathrm{C}_{3}$, the synthesis of PHUs was conducted. The PHUs obtained were characterized by ${ }^{1} \mathrm{H}$ NMR, FT-IR spectroscopy and SEC measurements and the results are summarized in Entry 1-3 in Table 1. The ${ }^{1} \mathrm{H}$ NMR spectrum of these PHUs is similar to that of $\mathrm{p}\left(\mathrm{Ph}-\mathrm{TMPC}_{2}-\mathrm{C}_{3}\right)$ (Figure S5 and S6). Conversion values are close to $100 \%$ and $M_{\mathrm{n}}$ and $M_{\mathrm{w}} / M_{\mathrm{n}}$ values are well corresponded to those of theoretical values.

PHUs can be modified with various functional groups via their hydroxyl side chains. After PHUs are reacted with acetic anhydride, acetylated PHUs can be obtained. Actually, we performed the acetylation of $\mathrm{p}\left(\mathrm{Ph}-\mathrm{TMPC}_{2}-\mathrm{C}_{3}\right)$ and acetylated PHU ( $\left.\left(\mathrm{Ph}-\mathrm{TMPC}_{2}-\mathrm{C}_{3}-\mathrm{OAc}\right)\right)$ was spectroscopically characterized. The ${ }^{1} \mathrm{H}$ NMR spectrum shown in Figure $\mathrm{S} 7$ reveals that the acetylation was adequately performed. On the other hand, $M_{\mathrm{n}}$ values determined by its SEC trace is lower than that theoretically calculated by its ${ }^{1} \mathrm{H}$ NMR spectrum (Entry 4 in Table 1), which would be caused by the potential difference of hydrodynamic radius from standard polystyrenes.

As shown in Scheme $4 \mathrm{~b}$, it is expected that the polyaddition of $\mathrm{Ph}_{-}-\mathrm{TMPC}_{2}$ and a slightly excess amount of diamine gives PHUs with amine terminals. We reacted 1.0 equiv. of $\mathrm{Ph}-\mathrm{TMPC}_{2}$ with 1.1 equiv. of $\mathrm{C}_{3}$. The ${ }^{1} \mathrm{H} \mathrm{NMR}$ spectrum of the resulting PHUs is shown in Figure S8. Differing from the spectrum of $\mathrm{p}\left(\mathrm{Ph}-\mathrm{TMPC}_{2}-\mathrm{C}_{3}\right)$ (Figure 3), the spectrum exhibits no signals at ca. $4.4 \mathrm{ppm}$ ascribed to cyclic carbonate terminals. The signal at 3.0-2.5 ppm derived from amine terminals is unclear because of the overlapping with other signals, however, its $M_{\mathrm{n}}$ and $M_{\mathrm{w}} / M_{\mathrm{n}}$ 
values are close to theoretical values (Entry 5 in Table 1). These results apparently suggest that PHUs with different terminal structures are individually synthesized depending on the changes in $\mathrm{Ph}-\mathrm{TMPC}_{2} /$ diamine feed ratios.

\subsection{Fabrication of Networked PHU Films}

To examine the formative ability of networked structures, we at first reacted $\mathrm{Ph}-\mathrm{TMPC}_{3}$ with $\mathrm{C}_{3}$ in $\mathrm{DMF}$ at $70{ }^{\circ} \mathrm{C}$. The reaction mixture (TMPC/ $\left.\mathrm{NH}_{2}=1.0\right)$ immediately changed to viscous solution and finally formed gels within 1 h. This behavior apparently indicates the formation of networked structures. Next, the DMF solutions of $\mathrm{Ph}-\mathrm{TMPC}_{2} / \mathrm{Ph}-\mathrm{TMPC}_{3} / \mathrm{C}_{3}$, in which mole ratios of $\mathrm{Ph}-\mathrm{TMPC}_{3}$ were $5-20 \mathrm{~mol} \%$ with respect to total carbonate monomer and the TMPC/ $\mathrm{NH}_{2}$ ratio was 1.0 , were kept in glass petri-dishes at $70{ }^{\circ} \mathrm{C}$ overnight. During this treatment, DMF was slowly evaporated and concomitantly the reaction of $\mathrm{Ph}-\mathrm{TMPC}_{2} / \mathrm{Ph}-\mathrm{TMPC}_{3}$ with $\mathrm{C}_{3}$ proceeded to form networked PHU films (Film A) in one-step. These films were quite stable and able to detach from the dishes. These films gave stretching vibrations assigned to carbonyl groups of urethane bonds at ca. 1650 $\mathrm{cm}^{-1}$ (data are not shown), indicating the formation of hydroxyurethane linkages. The photographs of these films are shown in Figure 4. All films are well transparent and flexible. Similarly, Film B and Film C, which were prepared using $20 \mathrm{~mol} \% \mathrm{Ph}-\mathrm{TMPC}_{3}$ with $\mathrm{C}_{6}$ or $\mathrm{C}_{12}$, respectively, are well transparent and flexible (Figure $5 \mathrm{e}, \mathrm{f}$ ). UV/Vis-NIR absorption spectra of Film A-C are shown in Figure 5. These films show more than $80 \%$ transmittance in 440-1600 nm. The Film A prepared at different amounts of $\mathrm{Ph}_{-} \mathrm{TMPC}_{3}$ also show same absorption spectra (Figure S9).

a)

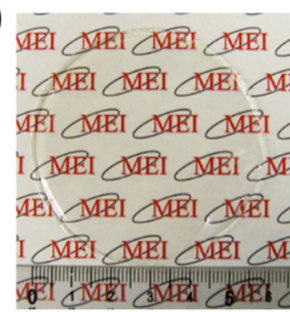

d)

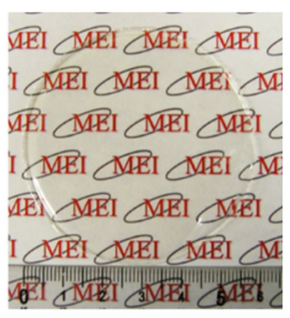

b)

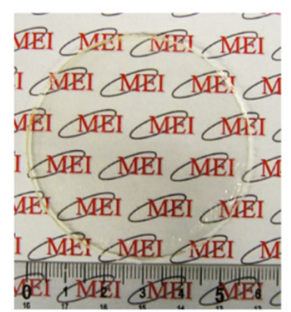

e)

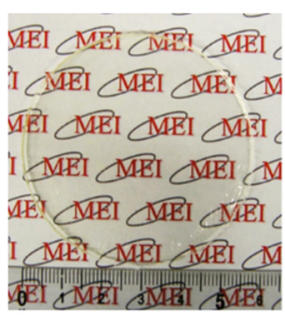

c)

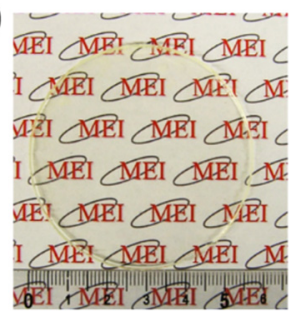

f)

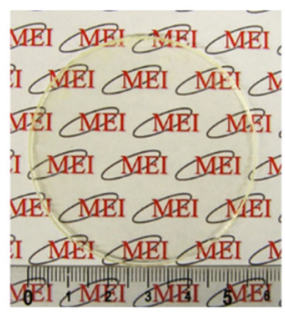

Figure 4. a-d) Photographs of Film A prepared from $\mathrm{Ph}-\mathrm{TMPC}_{2} / \mathrm{Ph}-\mathrm{TMPC}_{3} / \mathrm{C}_{3}$. The mole ratios of $\mathrm{Ph}-\mathrm{TMPC}_{3}$ are a) 5, b) 10 , c) 15 or d) $20 \mathrm{~mol} \%$ with respect to total carbonate monomers $\left(\mathrm{Ph}-\mathrm{TMPC}_{2}+\mathrm{Ph}-\mathrm{TMPC}_{3}\right)$. e) Film B prepared using $20 \mathrm{~mol} \% \mathrm{Ph}_{-} \mathrm{TMPC}_{3}$ and $\mathrm{C}_{6}$. f) Film C prepared using $20 \mathrm{~mol} \% \mathrm{Ph}-\mathrm{TMPC}_{3}$ and $\mathrm{C}_{12}$

TGA profiles of these films are shown in Figure 6._For Film A, a slight weight loss occurred at 100-200, which would be caused by the removal of adsorbed water molecules. After that, weights abruptly decreased at 250-300 ${ }^{\circ} \mathrm{C}$ and then the film was completely decomposed at $300-520{ }^{\circ} \mathrm{C}$. Since urethane bonds of polyurethane are decomposed at $300-500{ }^{\circ} \mathrm{C}$ (Nayak, 1997), the weight loss at $250-300{ }^{\circ} \mathrm{C}$ would be caused by the decomposition of diamine moieties. On the other hand, Film B and Film C gave gradual weight loss at $300-500{ }^{\circ} \mathrm{C}$ and showed the slightly higher thermal stability compared to Film A. This could be due to the stronger Van der Waals interactions among longer methylene spacers of diamines. TGA profiles of Film A prepared at different amounts of $\mathrm{Ph}-\mathrm{TMPC}_{3}$ are also shown in Figure S10. Without depending on the amounts of $\mathrm{Ph}-\mathrm{TMPC}_{3}$, the same thermal decomposition behavior was observed. Since even networked PHUs prepared using $100 \mathrm{~mol} \% \mathrm{Ph}-\mathrm{TMPC}_{3}$ gave the similar TGA profile (data are not shown), the density and amount of cross-linked structures do not seem to affect the thermal properties. 


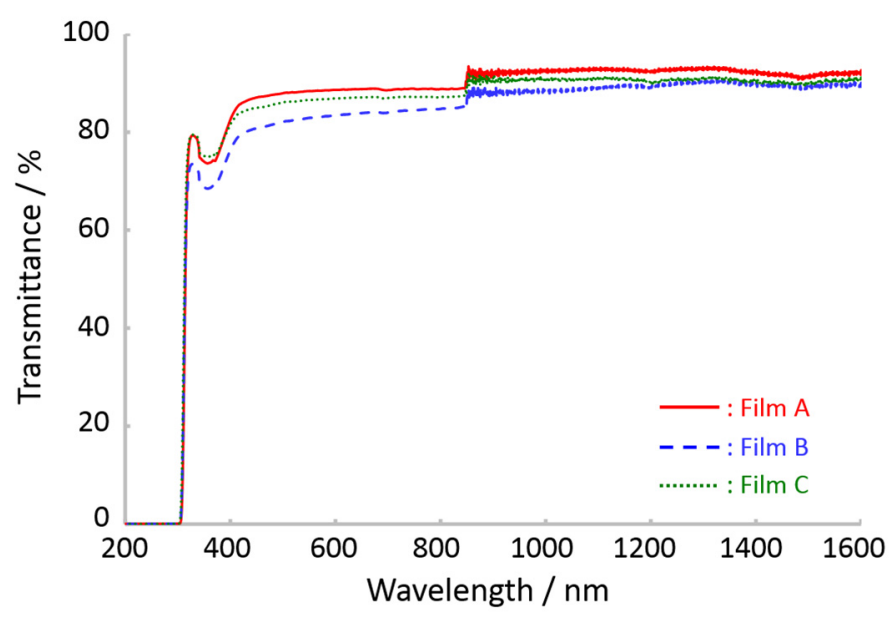

Figure 5 UV/Vis.-NIR absorption spectra of networked PHU films prepared from $20 \mathrm{~mol} \% \mathrm{Ph}-\mathrm{TMPC}_{3}$ and different diamines. Red solid line: Film A. Blue dashed line: Film B. Green dotted line: Film C

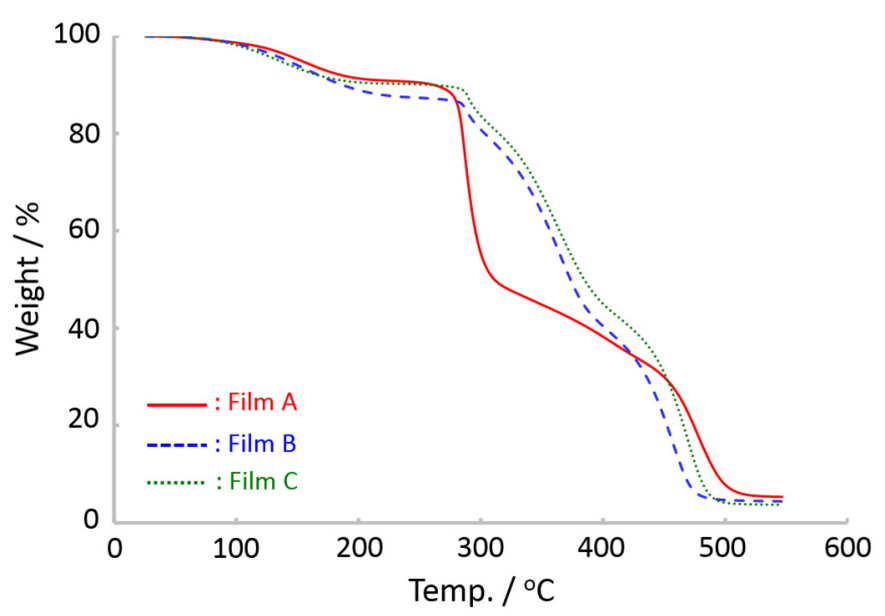

Figure 6 TGA profiles of networked PHU films prepared using $20 \mathrm{~mol} \% \mathrm{Ph}-\mathrm{TMPC}_{3}$ and different diamines. Red solid line: Film A. Blue dashed line: Film B. Green dotted line: Film C

These networked PHU films were investigated for their mechanical properties by tensile test. Representative stress-strain curves of these films are shown in Figure 7 and averaged mechanical parameters obtained from the curves are summarized in Table 2. Although these films showed similar transparency and thermal properties, their mechanical properties were quite different. Film A gave the yield point at $42.4 \mathrm{MPa}$ and then broken at an elongation of $50.1 \%$. Film A prepared using different amounts of $\mathrm{Ph}_{-} \mathrm{TMPC}_{3}$ showed similar curves (data are not shown). On the other hands, Film B and Film C elongated gradually without showing yield points and finally broken at longer than ca. $290 \%$ elongation points. From these results, it is apparent that mechanical properties of networked PHU films can be regulated by tuning the structures of diamines.

Table 2. Averaged mechanical parameters determined from Stress-strain curves of networked PHU films prepared using $20 \mathrm{~mol} \% \mathrm{Ph}_{-} \mathrm{TMPC}_{3}$ and different diamines.

\begin{tabular}{cccccc}
\hline Entry & Diamine & $\mathrm{E} / \mathrm{MPa}$ & $\sigma_{\text {yild }} / \mathrm{MPa}$ & $\sigma_{\text {break }} / \mathrm{MPa}$ & $\varepsilon_{\text {break }} / \%$ \\
\hline Film A & $\mathrm{C}_{3}$ & 7.1 & 42.4 & 24.3 & 50.1 \\
Film B & $\mathrm{C}_{6}$ & 0.38 & - & 8.6 & 296 \\
Film C & $\mathrm{C}_{12}$ & 0.70 & - & 11.0 & 402 \\
\hline
\end{tabular}




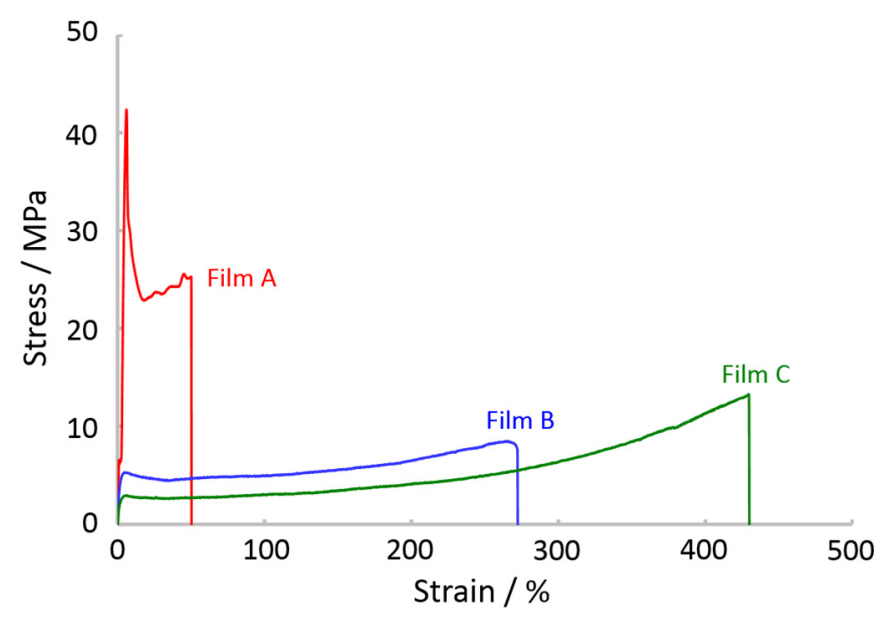

Figure 7 Representative stress-strain curves of networked PHU films prepared using $20 \mathrm{~mol} \% \mathrm{Ph}-\mathrm{TMPC}_{3}$ and different diamines. Red line: Film A. Blue line: Film B. Green line: Film C

\section{Conclusions}

In this paper, we have described the followings: i) the synthesis of bi- and trifunctional TMP-based cyclic carbonates $\left(\mathrm{Ph}-\mathrm{TMPC}_{2}\right.$ or $\mathrm{Ph}-\mathrm{TMPC}_{3}$ ) from TMPC-OH and the corresponding acyl chlorides, ii) the synthesis of linear PHUs by the ring-opening polyaddition of $\mathrm{Ph}-\mathrm{TMPC}_{2}$ and conventional diamines, iii) the fabrication of networked PHU materials by the copolymerization of $\mathrm{Ph}-\mathrm{TMPC}_{2}, \mathrm{Ph}_{-} \mathrm{TMPC}_{3}$ and diamines. The reaction of TMP and 4 equiv. of DPC at $140{ }^{\circ} \mathrm{C}$ for $1-2$ days gives mainly TMPC-OH and the reaction of TMPC-OH and terephthaloyl chloride or trimesoyl chloride affords $\mathrm{Ph}-\mathrm{TMPC}_{2}$ or $\mathrm{Ph}-\mathrm{TMPC}_{3}$, respectively. Ring-opening polyaddition of $\mathrm{Ph}_{-} \mathrm{TMPC}_{2}$ and conventional diamines effectively proceeded without the cleavage of ester bonds to give PHUs with well-controlled molecular weights and polydispersities. By changing the $\mathrm{Ph}-\mathrm{TMPC}_{2} /$ diamine feed ratios, we could obtain PHUs with different terminal structures. The copolymerization of $\mathrm{Ph}_{-} \mathrm{TMPC}_{2}$, small amounts of $\mathrm{Ph}_{-} \mathrm{TMPC}_{3}$ and diamines forms effectively covalently-crosslinked structures and then networked PHU films are readily fabricated. The resulting films showed similar transparency and thermal stability, while the mechanical properties were significantly affected by the methylene spacers of diamines.

In our approach, PHUs are derived from non-expensive reagents via non-phosgene derivatives and non-isocyanate routes in whole processes. Networked PHUs are simply obtainable by copolymerization of bi- and trifunctional cyclic carbonates and diamines in one step without further chemical modification of hydroxyl side chines. Our approach will be one of the fundamental for designing PHU-based networked films.

\section{Acknowledgments}

This work was financially supported by JSR Co., Ltd.

\section{References}

Annunziata, L., Diallo, A. K., Fouquay, S., Michaud, G., Simon, F., Brusson, J.-M., Carpentier, J.-F., \& Guillaume, S. M. (2014). $\alpha, \omega$-Di(glycerol carbonate) telechelic polyesters and polyolefins as precursors to polyhydroxyurethanes: an isocyanate-free approach. Green Chem., 16, 1947-1956. http://dx.doi.org/10.1039/C3GC41821A

Fleischer, M., Blattmann, H., \& Mülhaupt, R. (2013). Glycerol-, pentaerythritol- and trimethylolpropane-based polyurethanes and their cellulose carbonate composites prepared via the non-isocyanate route with catalytic carbon dioxide fixation. Green Chem., 15, 934-942. http://dx.doi.org/10.1039/C3GC00078H

Guillaume, S. M. (2013). Recent advances in ring-opening polymerization strategies toward $\alpha, \omega$-hydroxyl telechelic polyesters and resulting copolymers. Eur. Polym. J., 49, 768-779. http://dx.doi.org/10.1016/j. eurpolymj.2012.10.011

He, Y., Keul, H., \& Möller, M. (2011). Synthesis, characterization, and application of a bifunctional coupler containing a five- and a six-membered ring carbonate. React. Funct. Polym., 71, 175-186. http://dx.doi.org/10.1016/j.reactfunctpolym.2010.11.031 
Helou, M., Carpentier, J.-F., \& Guillaume, S. M. (2011). Poly(carbonate-urethane): an isocyanate-free procedure from $\alpha, \omega$-di(cyclic carbonate) telechelic poly(trimethylene carbonate)s. Green Chem., 13, 266-271. http://dx.doi.org/10.1039/C0GC00686F

Kanega, R., Hayashi, T., \& Yamanaka, I. (2013). Pd(NHC) electrocatalysis for phosgene-free synthesis of diphenyl carbonate. ACS Catal., 3, 389-392. http://dx.doi.org/10.1021/cs300725j

Kathalewar, M., Joshi, P., Sabnis, A., \& Malshe, V. (2013). Non-isocyanate polyurethanes: from chemistry to applications. $R S C A d v$., 3, 4110-4129. http://dx.doi.org/10.1039/C2RA21938G

Kathalewar, M., \& Sabnis, A. (2015). Preparation of novel CNSL-based urethane polyol via nonisocyanate route: Curing with melamine-formaldehyde resin and structure-property relationship. J. Appl. Polym. Sci., 132, 41391. http://dx.doi.org/10.1002/APP.41391

Kihara, N., Kushida, Y., \& Endo, T. (1996). Optically active poly(hydroxyurethane)s derived from cyclic carbonate and L-lysine derivatives. J. Polym. Sci. Part A: Polym. Chem., 34, 2173-2179. http://dx.doi.org/10.1002/(SICI)1099-0518(199608)34:11<2173::AID-POLA10>3.0.CO;2-C.

Lambeth, R. H., \& Henderson, T. J. (2013). Organocatalytic synthesis of (poly)hydroxyurethanes from cyclic carbonates and amines. Polymer, 54, 5568-5573. http://dx.doi.org/10.1016/j.polymer.2013.08.053

Maisonneuve, L., More, A. S., Foltran, S., Alfos, C., Robert, F., Landais, Y., Tassaing, T., Grau, E., \& Cramail, H. (2014). Novel green fatty acid-based bis-cyclic carbonates for the synthesis of isocyanate-free poly(hydroxyurethane)s. $R S C A d v$., 4, 25795-25803. http://dx.doi.org/10.1039/C4RA03675A

Maisonneuve, L., Wirotius, A.-L., Alfos, C., Grau, E., \& Cramail, H. (2014). Fatty acid-based (bis) 6-membered cyclic carbonates as efficient isocyanate free poly(hydroxyurethane) precursors. Polym. Chem., 5, 6142-6147. http://dx.doi.org/10.1039/C4PY00922C

Matsukizono, H., \& Endo, T. (2015). Mono- and bifunctional six-membered cyclic carbonates synthesized by diphenyl carbonate toward networked polycarbonate films. J. Appl. Polym. Sci., 132, 41956. http://dx.doi.org/10.1002/app.41956

Matsukizono, H., \& Endo, T. (2016). Ring-opening polymerization of six-membered cyclic carbonates initiated by ethanolamine derivatives and their application to protonated- or quaternary ammonium salt-functionalized polycarbonate films. J. Polym. Sci. Part A: Polym. Chem., 54, 487-497. http://dx.doi.org/10.1002/pola.27922

Matsukizono, H., \& Endo, T. (2015). Synthesis of polyhydroxyurethanes from di(trimethylolpropane) and their application to quaternary ammonium chloride-functionalized films. RSC $A d v$., 5, 71360-71369. http://dx.doi.org/10.1039/C5RA09885H

Matsukizono, H., \& Endo, T. (2016). Synthesis and hydrolytic properties of water-soluble poly(carbonate-hydroxyurethane)s from trimethylolpropane. Polym. Chem., 7, 958-969. http://dx.doi.org/10. 1039/C5PY01733E

Murayama, T., Hayashi, T., Kanega, R., \& Yamanaka, I. (2012). Phosgene-free method for diphenyl carbonate synthesis at the $\mathrm{Pd}^{0} /$ Ketjenblack anode. J. Phys. Chem. C, 116, 10607-10616. http://dx.doi.org/10.1021/jp300809s

Nayak, P., Mishra, D. K., Parida, D., Sahoo, K. C., Nanda, M., Lenka, S., \& Nayak, P. L. (1997). Polymers from renewable resources. IX. Interpenetrating polymer networks based on castor oil polyurethane poly(hydroxyethyl methacrylate): Synthesis, chemical, thermal, and mechanical properties. J. Appl. Polym. Sci., 63, 671-679. http://dx.doi.org/10.1002/(SICI)1097-4628(19970131)63:5<671::AID-APP15>3.0.CO;2-X

Nishihara, R. (2010). The novel process for diphenyl carbonate and polycarbonate production. Catal. Surv. Asia, 14, 140-145. http://dx.doi.org/10.1007/s10563-010-9095-3

Nohra, B., Candy, L., Blanco, J.-F., Guerin, C., Raoul, Y., \& Mouloungui, Z. (2013). From petrochemical polyurethanes to biobased polyurethanes. Macromolecules, 46, 3771-3792. http://dx.doi.org/10.1021/ma $400197 \mathrm{c}$

Ochiai, B., Kojima, H., \& Endo, T. (2014). Synthesis and properties of polyhydroxyurethane bearing silicone backbone. J. Polym. Sci. Part A: Polym. Chem., 52, 1113-1118. http://dx.doi.org/10.1002/pola.27091

Ochiai, B., Sato, S., \& Endo, T. (2007). Crosslinkable polyurethane bearing a methacrylate structure in the side chain. J. Polym. Sci. Part A: Polym. Chem., 45, 3400-3407. http://dx.doi.org/10.1002/pola.22092 
Ochiai, B., Sato, S., \& Endo, T. (2007). Synthesis and properties of polyurethanes bearing urethane moieties in the side chain. J. Polym. Sci. Part A: Polym. Chem., 45, 3408-3414. http://dx.doi.org/10.1002/pola.22093

Ochiai, B., Satoh, Y., \& Endo, T. (2005). Nucleophilic polyaddition in water based in chemo-selective reaction of cyclic carbonate with amine. Green Chem., 7, 765-767. http://dx.doi.org/10.1039/B511019J

Ochiai, B., Inoue, S., \& Endo, T. (2005). One-pot non-isocyanate synthesis of polyurethanes from bisepoxide, carbon dioxide, and diamine. J. Polym. Sci. Part A: Polym. Chem., 43, 6613-6618. http://dx.doi.org/10.1002/pola.21103

Ochiai, B., Nakayama, J., Mashiko, M., Kaneko, Y., Nagasawa, T., \& Endo, T. (2005). Synthesis and crosslinking reaction of poly(hydroxyurethane) bearing a secondary amine structure in the main chain. $J$. Polym. Sci. Part A: Polym. Chem., 43, 5899-5905. http://dx.doi.org/10.1002/pola.21078

Okuyama, K., Sugiyama, J., Nagahata, R., Asai, M., Ueda, M., \& Takeuchi, K. (2003). An environmentally benign process for aromatic polycarbonate synthesis by efficient oxidative carbonylation catalyzed by Pd-carbene complexes. Green Chem., 5, 563-566. http://dx.doi.org/10.1039/B304878K

Sheng, X., Ren, G., Qin, Y., Chen, X., Wang, X., \& Wang, F. (2015). Quantitative synthesis of bis(cyclic carbonate)s by iron catalyst for non-isocyanate polyurethane synthesis. Green Chem., 17, 373-379. http://dx.doi.org/10.1039/C4GC01294A

Tomita, H., Sanda, F., \& Endo, T. (2001). Polyaddition behavior of bis(five- and six-membered cyclic carbonate)s with diamine. J. Polym. Sci. Part A: Polym. Chem., 39, 860-867. http://dx.doi.org/10.1002/1099-0518(20010315)39:6<860::AID-POLA1059>3.0.CO;2-2

Tomita, H., Sanda, F., Endo, T. (2001). Reactivity comparison of five- and six-membered cyclic carbonates with amines: Basic evaluation for synthesis of poly(hydroxyurethane). J. Polym. Sci. Part A: Polym. Chem., 39, 162-168. http://dx.doi.org/10.1002/1099-0518(20010101)39:1<162::AID-POLA180>3.0.CO;2-O 


\section{Appendix}

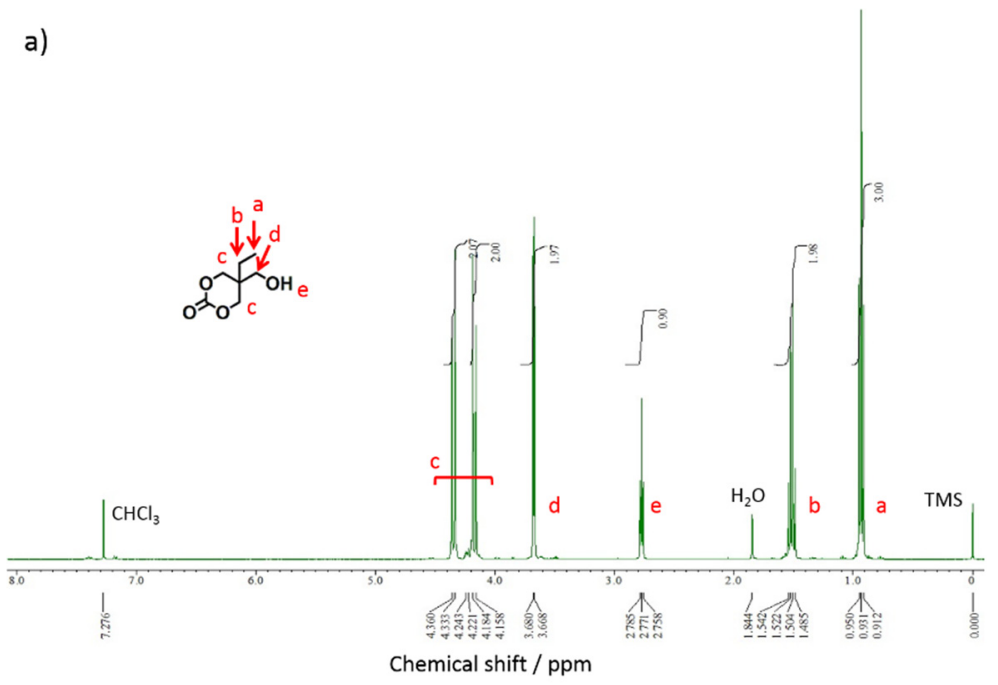

b)

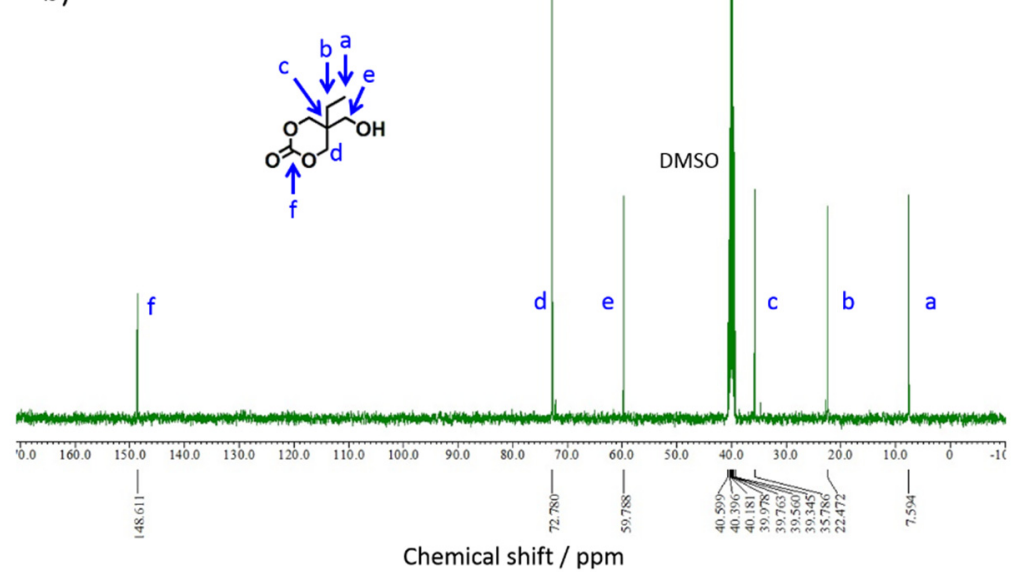

Figure S1. NMR spectra of TMPC-OH after purification by column chromatography. a) ${ }^{1} \mathrm{H}$ NMR spectrum in $\mathrm{CDCl}_{3}$ with $0.03 \mathrm{v} / \mathrm{v} \%$ of TMS. b) ${ }^{13} \mathrm{C}$ NMR spectrum in DMSO- $\mathrm{d}_{6}$

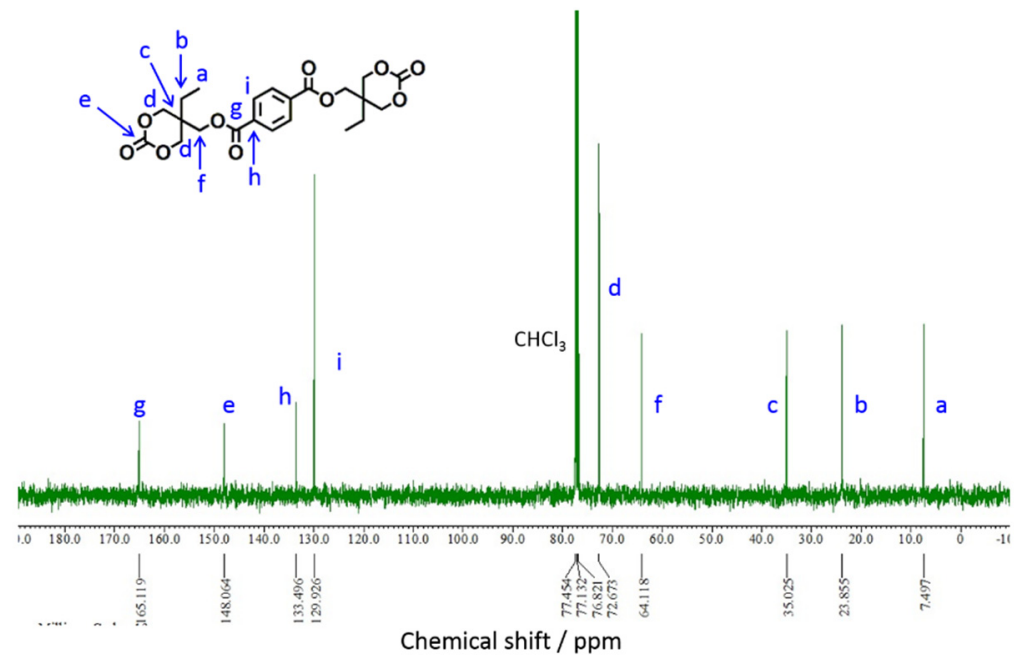

Figure S2. ${ }^{13} \mathrm{C}$ NMR spectrum of $\mathrm{Ph}-\mathrm{TMPC}_{2}$ in $\mathrm{CDCl}_{3}$ containing $0.03 \mathrm{v} / \mathrm{v} \%$ of TMS. 


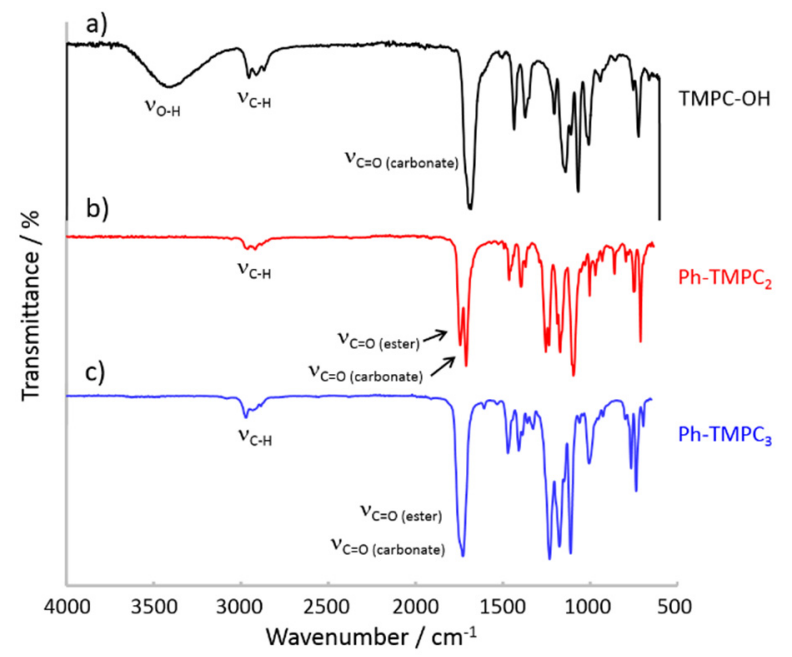

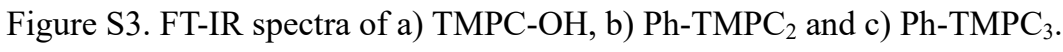
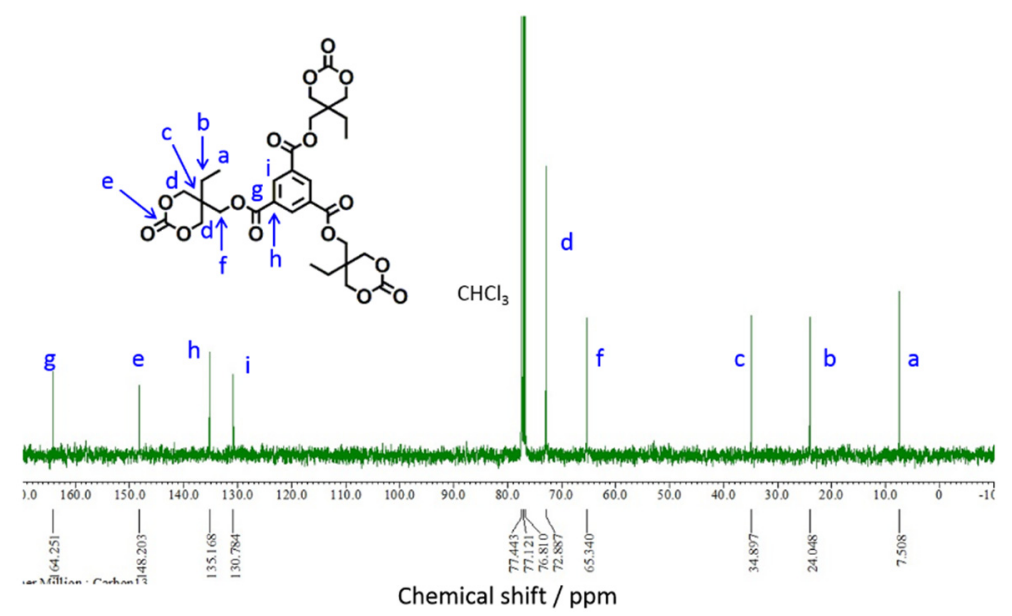

Figure S4. ${ }^{13} \mathrm{C}$ NMR spectrum of $\mathrm{Ph}-\mathrm{TMPC}_{3}$ in $\mathrm{CDCl}_{3}$ containing $0.03 \mathrm{v} / \mathrm{v} \%$ of TMS.

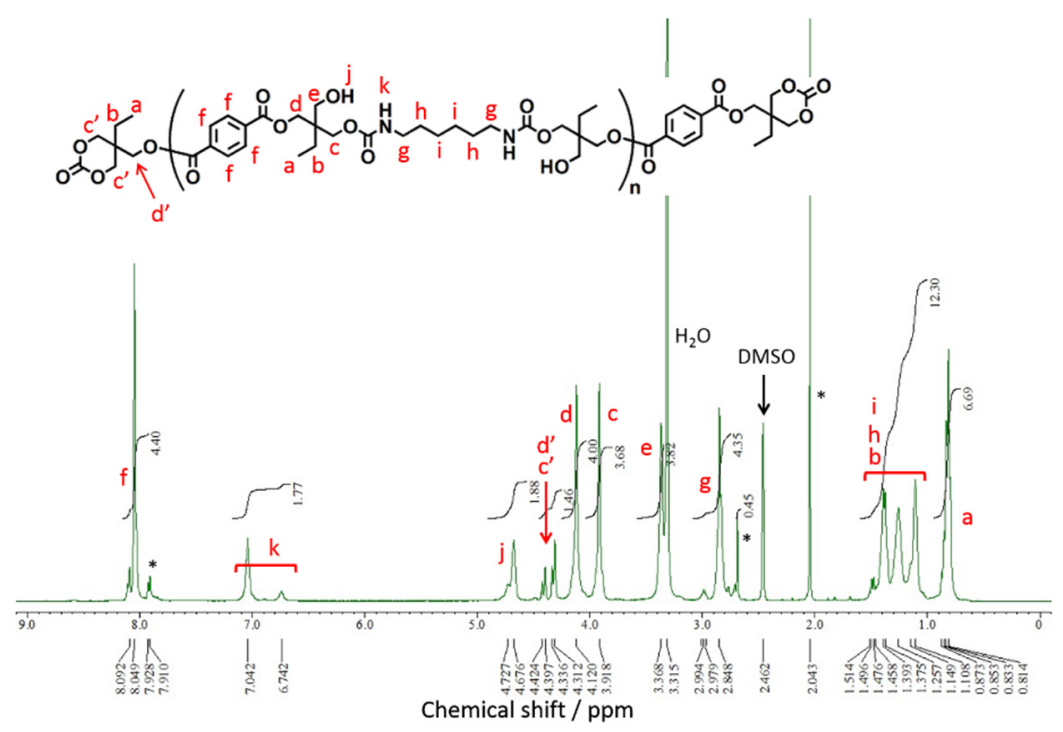

Figure S5. ${ }^{1} \mathrm{H}$ NMR spectrum of $\mathrm{p}\left(\mathrm{Ph}-\mathrm{TMPC}_{2}-\mathrm{C}_{6}\right)$ in DMSO- $\mathrm{d}_{6}$. Asterisks mean residual solvents (DMF and acetone) 


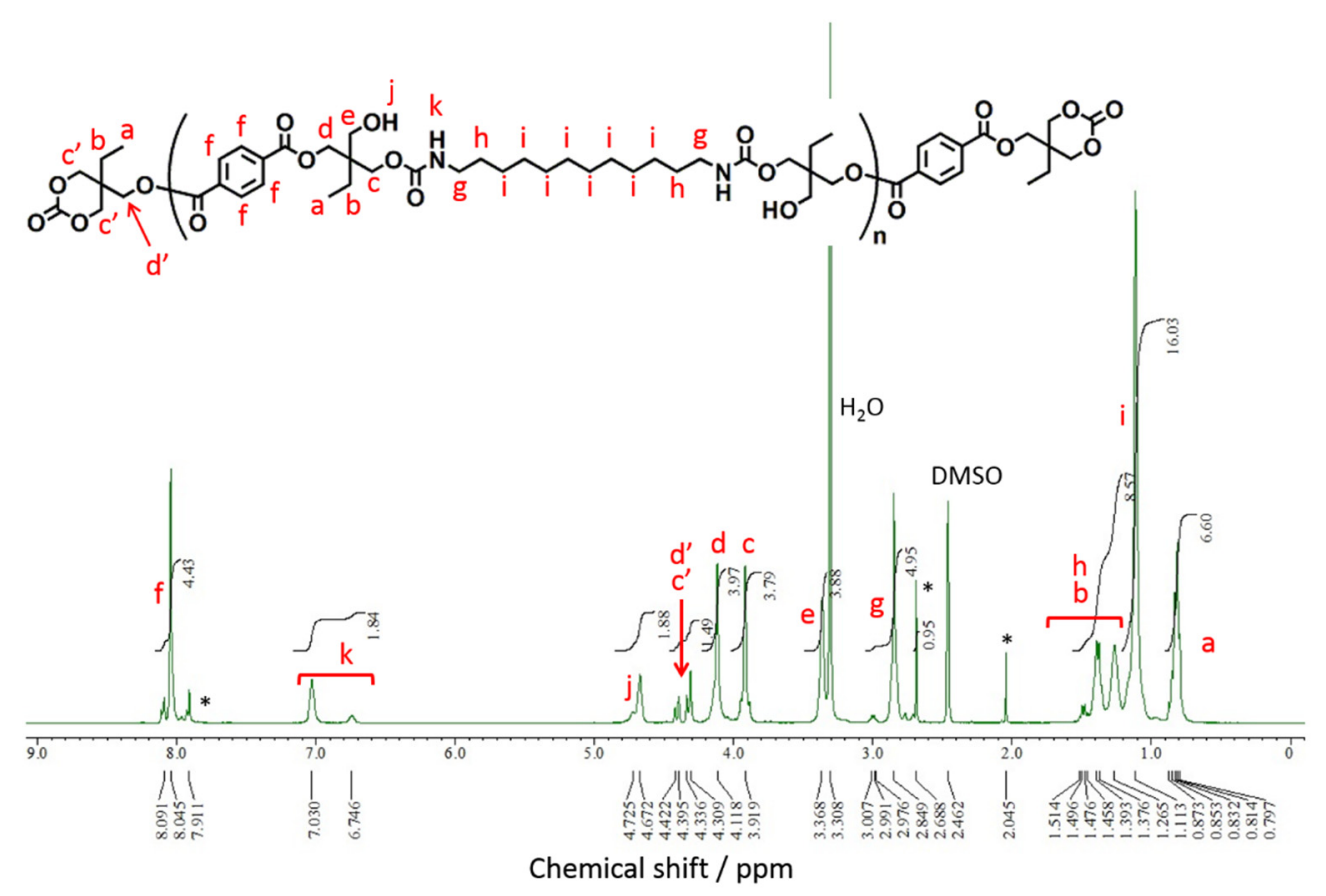

Figure S6. ${ }^{1} \mathrm{H}$ NMR spectrum of $\mathrm{p}\left(\mathrm{Ph}-\mathrm{TMPC}_{2}-\mathrm{C}_{12}\right)$ in DMSO- $\mathrm{d}_{6}$. Asterisks mean residual solvents (DMF and acetone).

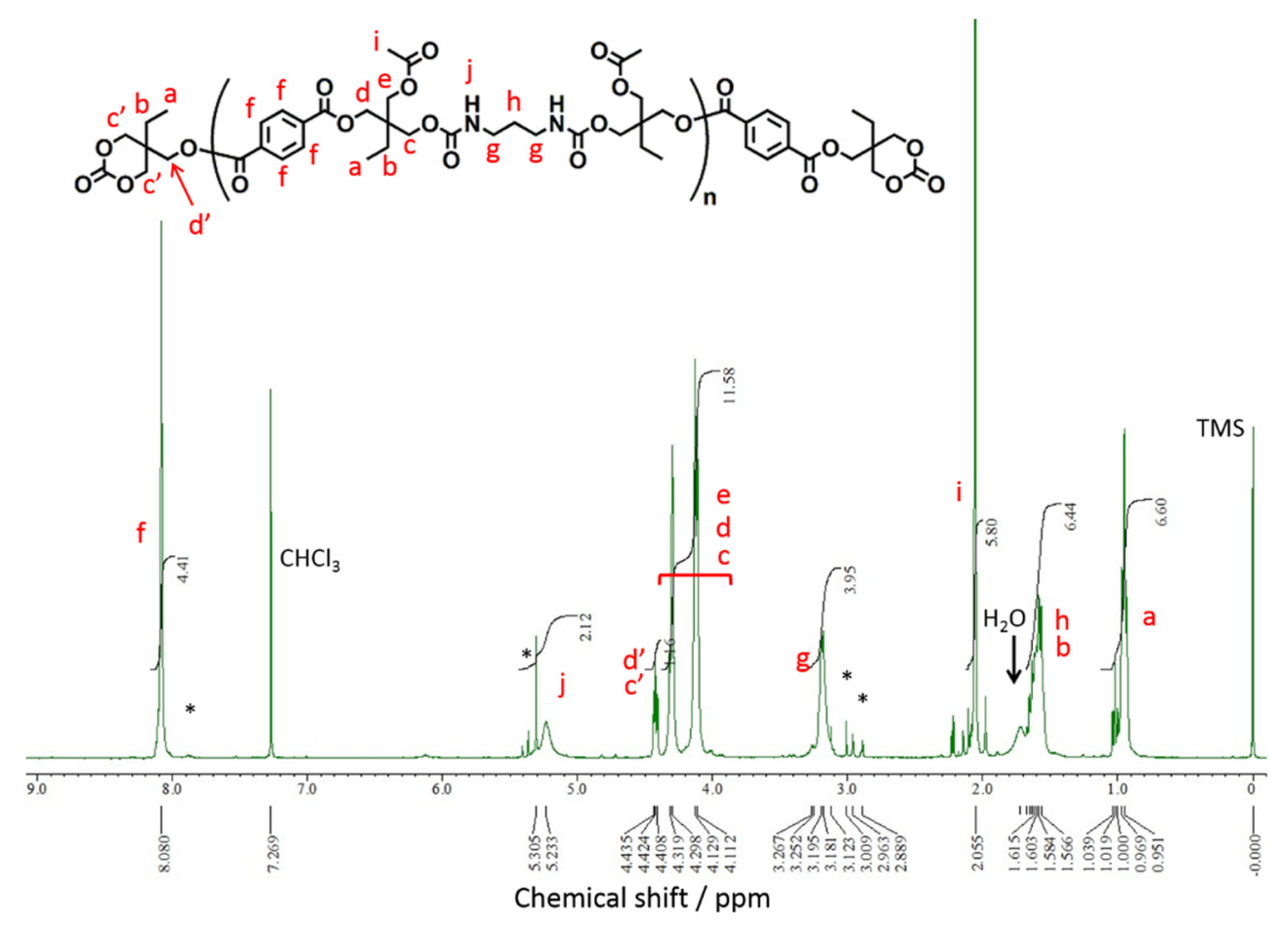

Figure S7. ${ }^{1} \mathrm{H}$ NMR spectrum of $\mathrm{p}\left(\mathrm{Ph}-\mathrm{TMPC}_{2}-\mathrm{C}_{3}-\mathrm{OAc}\right)$ in $\mathrm{CDCl}_{3}$ containing $0.03 \mathrm{v} / \mathrm{v} \%$ of TMS. Asterisks denote residual solvents $\left(\mathrm{CH}_{2} \mathrm{Cl}_{2}\right.$ and $\left.\mathrm{DMF}\right)$. 


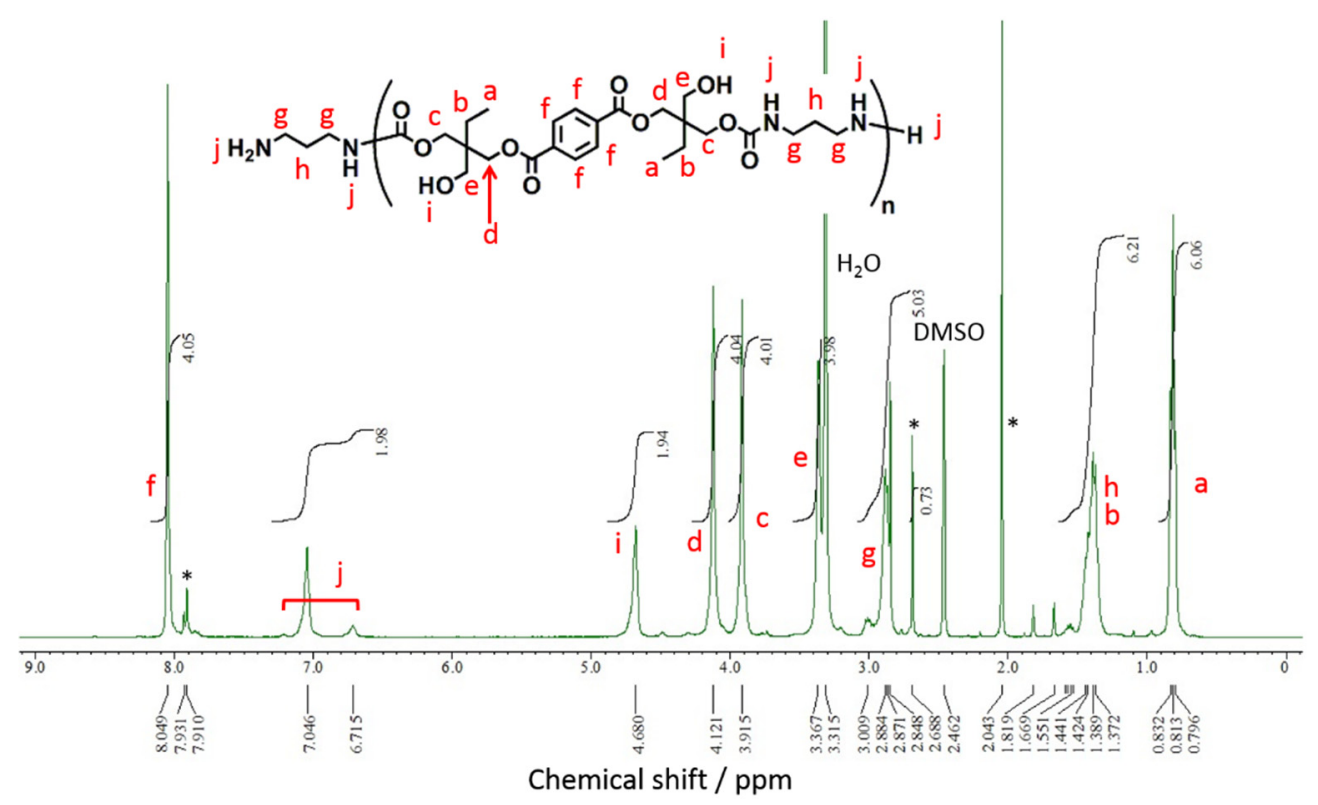

Figure S8. ${ }^{1} \mathrm{H}$ NMR spectrum of $\mathrm{p}\left(\mathrm{Ph}-\mathrm{TMPC}_{2}-\mathrm{C}_{3}\right)$ ' in DMSO- $\mathrm{d}_{6}$. Asterisks denote residual solvents (DMF and acetone)

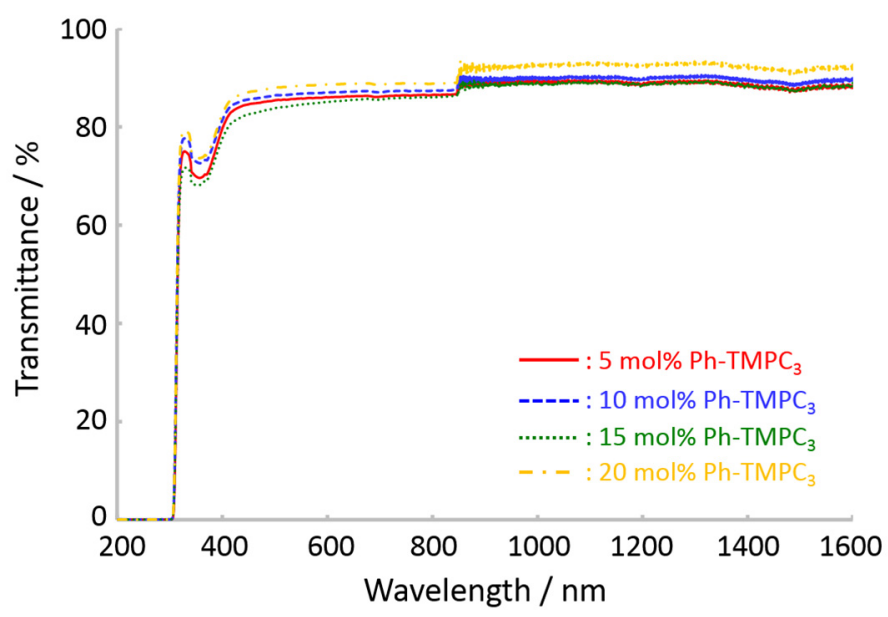

Figure S9. UV/Vis.-NIR absorption spectra of Film A prepared at different $\mathrm{Ph}-\mathrm{TMPC}_{2} / \mathrm{Ph}-\mathrm{TMPC}_{3} / \mathrm{C}_{3}$ feed ratios. The mole ratios of $\mathrm{Ph}_{-} \mathrm{TMPC}_{3}$ are 5 (red solid line), 10 (blue dashed line), 15 (green dotted line) or $20 \mathrm{~mol} \%$ (orange dashed and dotted line) with respect to total carbonate monomers $\left(\mathrm{Ph}-\mathrm{TMPC}_{2}+\mathrm{Ph}-\mathrm{TMPC}_{3}\right)$ 


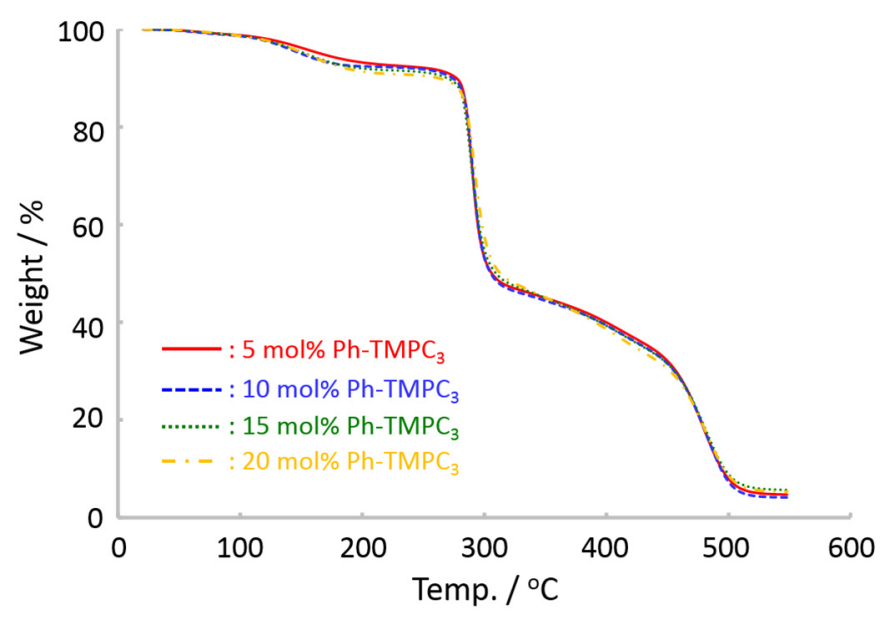

Figure S10. TGA profiles of Film A prepared at different $\mathrm{Ph}-\mathrm{TMPC}_{2} / \mathrm{Ph}-\mathrm{TMPC}_{3} / \mathrm{C}_{3}$ feed ratios. The mole ratios of $\mathrm{Ph}_{-} \mathrm{TMPC}_{3}$ are 5 (red solid line), 10 (blue dashed line), 15 (green dotted line) or $20 \mathrm{~mol} \%$ (orange dashed and dotted line) with respect to total carbonate monomers ( $\left.\mathrm{Ph}-\mathrm{TMPC}_{2}+\mathrm{Ph}-\mathrm{TMPC}_{3}\right)$.

\section{Copyrights}

Copyright for this article is retained by the author(s), with first publication rights granted to the journal.

This is an open-access article distributed under the terms and conditions of the Creative Commons Attribution license (http://creativecommons.org/licenses/by/3.0/). 